\title{
Intercropping with resistant cultivars reduces early blight and root knot disease on susceptible cultivars of tomato (Lycopersicon esculentum)
}

Linley Joy Smith

West Virginia University

Follow this and additional works at: https://researchrepository.wvu.edu/etd

\section{Recommended Citation}

Smith, Linley Joy, "Intercropping with resistant cultivars reduces early blight and root knot disease on susceptible cultivars of tomato (Lycopersicon esculentum)" (2002). Graduate Theses, Dissertations, and Problem Reports. 1536.

https://researchrepository.wvu.edu/etd/1536

This Thesis is protected by copyright and/or related rights. It has been brought to you by the The Research Repository @ WVU with permission from the rights-holder(s). You are free to use this Thesis in any way that is permitted by the copyright and related rights legislation that applies to your use. For other uses you must obtain permission from the rights-holder(s) directly, unless additional rights are indicated by a Creative Commons license in the record and/ or on the work itself. This Thesis has been accepted for inclusion in WVU Graduate Theses, Dissertations, and Problem Reports collection by an authorized administrator of The Research Repository @ WVU. For more information, please contact researchrepository@mail.wvu.edu. 


\title{
INTERCROPPING WITH RESISTANT CULTIVARS REDUCES EARLY BLIGHT AND ROOT KNOT DISEASE ON SUSCEPTIBLE CULTIVARS OF TOMATO (LYCOPERSICON ESCULENTUM)
}

\author{
Linley Joy Smith
}

\begin{abstract}
Thesis submitted to the Davis College of Agriculture, Forestry and Consumer Sciences at West Virginia University in partial fulfillment of the requirements for the degree of

Master of Science in

Plant and Soil Sciences
\end{abstract}

\author{
James B. Kotcon, Ph.D., Chair \\ Joseph B. Morton, Ph.D. \\ Daniel G. Panaccione, Ph.D. \\ Sven Verlinden, Ph.D. \\ Morgantown, West Virginia \\ 2002
}

Keywords: Alternaria solani, intercropping, Meloidogyne incognita, salicylic acid, tomato 


\begin{abstract}
Intercropping with Resistant Cultivars Reduces Early Blight and Root Knot

Disease on Susceptible Cultivars of Tomato (Lycopersicon esculentum)
\end{abstract}

\title{
Linley Joy Smith
}

The objective of this research was to determine if disease on susceptible tomato cultivars is reduced by intercropping with resistant cultivars. A second objective was to investigate the mechanism of the disease reduction observed. Early blight (caused by Alternaria solani) rate of disease increase and lesion expansion were lower on susceptible tomato cv. 'Brandywine' when intercropped with resistant cv. 'Juliet' than with 'Brandywine' monoculture in both the field and greenhouse. Yield from 'Brandywine' plants was $17.3 \%$ greater when intercropped with 'Juliet' than when grown in monoculture. Reduction in lesion expansion on 'Brandywine' when intercropped with 'Juliet' suggests an interaction initiating a defense response in 'Brandywine'. Increase in foliar salicylic acid (SA) concentration was greater in 'Juliet' than in 'Brandywine' following inoculation with $A$. solani, indicating that SA accumulation may contribute to increased resistance in 'Juliet'. In greenhouse experiments, there was a trend toward increased production of salicylic acid content in the leaves of 'Brandywine' when planted with resistant cultivars compared to those next to 'Brandywine', however this was not statistically significant. In addition, SA production 72 hours after inoculation with $A$. solani in the greenhouse was correlated with resistance in the field on 16 cultivars of tomato. A reduction in the spread of the parasitic nematode Meloidogyne incognita to 'Brandywine' when interplanted with root knot disease resistant cultivar 'Celebrity' was observed in the greenhouse. Results suggest that intercropping with resistant cultivars is effective in reducing diseases on susceptible cultivars caused by diverse pathogens. The main mechanism of disease reduction is attributed to reduced susceptible leaf material in the plot, however the potential for induced resistance in 'Brandywine' is discussed. 


\section{ACKNOWLEDGEMENTS}

I wish to express appreciation to Dr. James Kotcon for his assistance in the formulation and execution of the ideas for this project and for analysis and interpretation of the data. He has my gratitude for being a positive, patient mentor that always challenged and believed in me. My thanks is also extended to Dr. Joseph Morton, Dr. Daniel Panaccione and Dr. Sven Verlinden for the editing of numerous drafts of the thesis and for encouraging me to investigate into ideas that may have seemed far reaching. I would especially like to thank Dr. Daniel Panaccione for helping me to learn the salicylic acid extraction procedure and for providing the support for my desire to uncover the details of systemic acquired resistance. I thank Bill Wheeler for his help in preparing mycorrhizal inoculum and isolation of mycorrhizal hyphae, and Dr. Louis McDonald for use of his HPLC. In addition, I thank the organic farm interns, including Sabrina Dowdy, Amanda Oaks, Jason Parish, and Naoko Watanabe who helped to plant, mulch, stake, and gather data on the 1600 tomato plants for the intercropping experiments. Finally, I wish to express the deepest gratitude to my family for inspiring my enthusiasm for learning and supporting me in every step toward accomplishing this goal.

Seed for the tomato cultivar trial was kindly donated by Johnny's Selected Seeds Co., Albion, Maine. This research was supported by the West Virginia University Agricultural Experiment Station as part of Hatch project 384 and 411, by the USDA National Research Initiative Competitive Grant Program and the Organic Farm Research Foundation. 


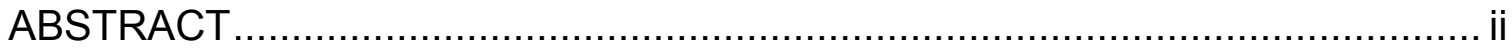

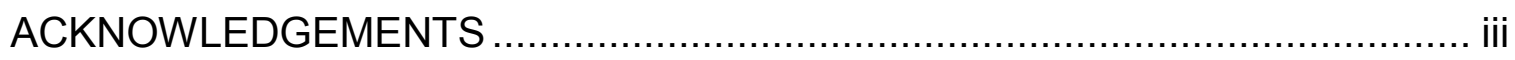

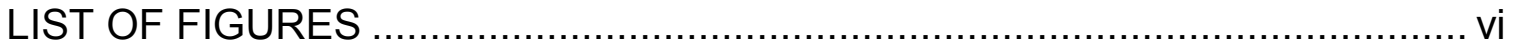

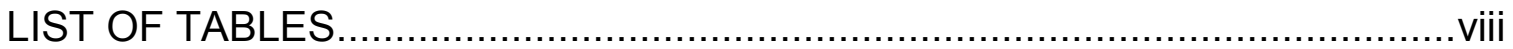

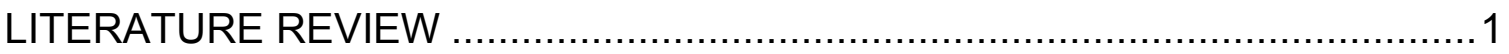

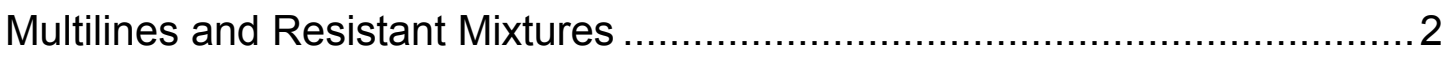

Mechanisms for Disease Reduction in Cultivar Mixtures ...............................

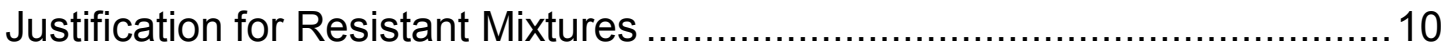

Why Resistant Mixtures Are Not Widely Used......................................... 10

Conclusions and Recommendations for Further Research .........................11

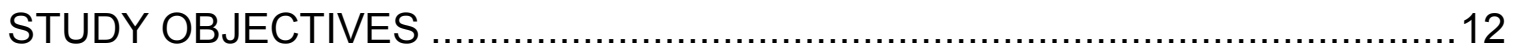

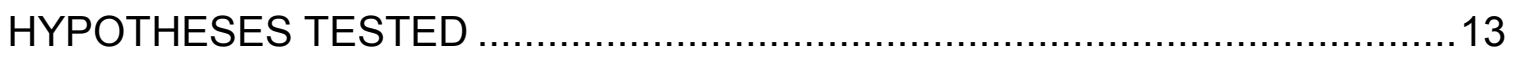

CHAPTER 1 Determination of resistance to Alternaria solani and Meloidogyne incognita in tomato cultivars...................................................................... 14

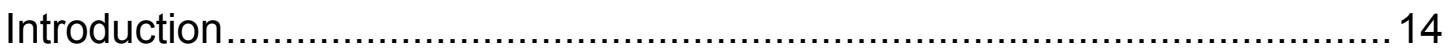

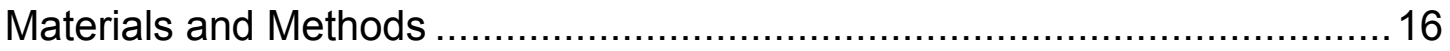

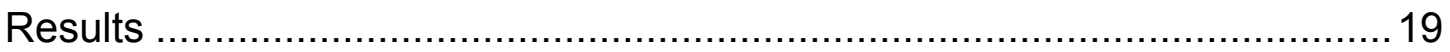

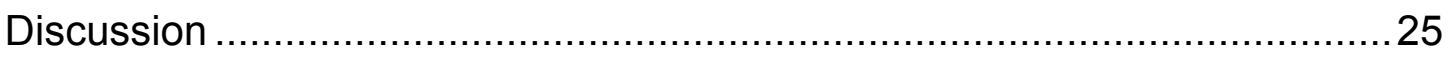

CHAPTER 2 The effects of intercropping with resistant tomato cultivars on the symptom expression of Alternaria solani, and Meloidogyne incognita to tomato cultivar 'Brandywine' in the greenhouse and field. .......................................28

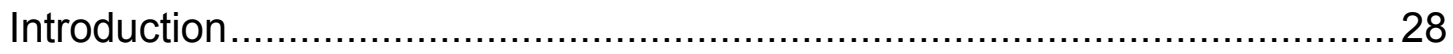

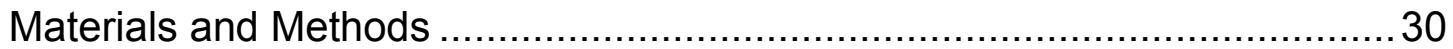

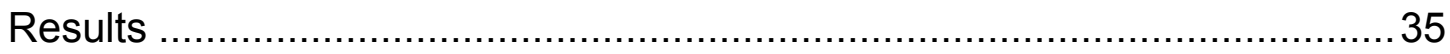

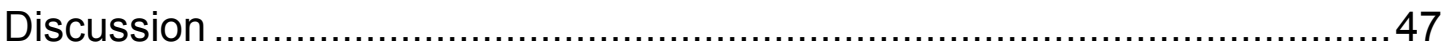

CHAPTER 3 Salicylic acid production as an indicator of the induction of resistance to Alternaria solani in intercropped tomato. ...................................51

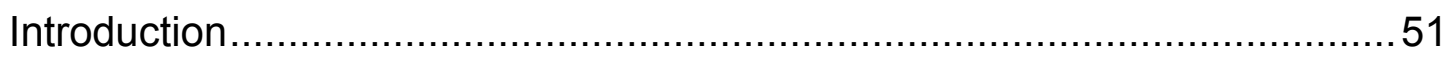

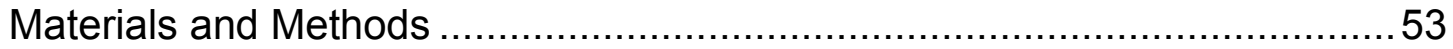

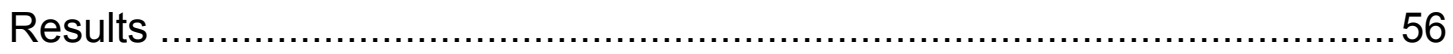




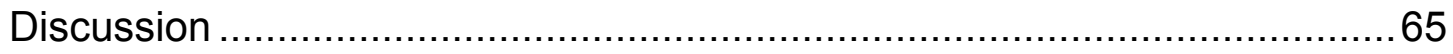

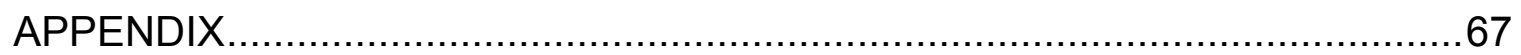

Detection of Salicylic Acid in the Hyphae of Vesicular Arbuscular Mycorrhizae Infecting Tomato After Inoculation with Pseudomonas syringae pv. phaseolicola.

Methods




\section{LIST OF FIGURES}

Figure

Page

Figure 1.1. Reproductive index $(R) 8$ weeks after inoculation of four tomato cultivars with $M$. incognita with 0,300 , or 3000 eggs per plant..

Figure 1.2. Number of $M$. incognita eggs recovered $\left(P_{f}\right)$ on four tomato cultivars 8 weeks after inoculation with 0,300 , or 3000 eggs per plant. .22

Figure 1.3. Galls per gram of root on four tomato cultivars 8 weeks after inoculation with 0,300 , or $3000 \mathrm{M}$. incognita eggs per plant.

Figure 1.4. Shoot dry weight of four tomato cultivars 8 weeks after inoculation with 0,300 , or 3000 eggs of $M$. incognita per plant.

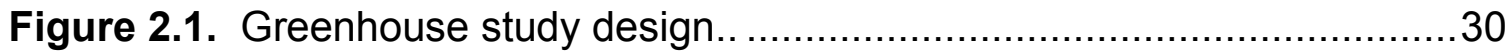

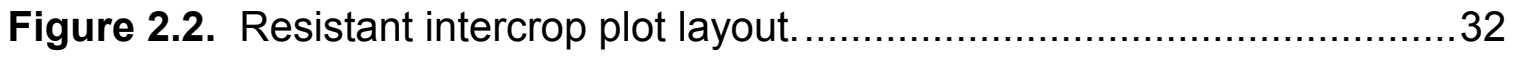

Figure 2.4. Percent leaf tissue of 'Brandywine' (plant 3) with early blight symptoms when planted next to one of three cultivars.

Figure 2.5. Diameter of the largest lesion on leaf 3 of 'Brandywine' (plant 3 ) when planted next to one of three cultivars.

Figure 2.6. Diameter of the largest lesion on leaf 9 of 'Brandywine' (plant 3) when planted next to one of three cultivars.

Figure 2.7. Number of early blight lesions on leaf 3 of 'Brandywine' (plant 3 ) when planted next to one of three cultivars.

Figure 2.8. Number of early blight lesions on leaf 9 of 'Brandywine' (plant 3 ) when planted next to one of three cultivars.

Figure 2.9. Mean number of $M$. incognita eggs recovered on 'Brandywine' (plant 3) planted next to the same cultivar, a root knot resistant cultivar ('Celebrity'), or another susceptible cultivar ('Juliet').

Figure 2.10. Mean number of galls per gram of root on 'Brandywine' (plant 3 ) planted next to the same cultivar, a root knot resistant cultivar ('Celebrity'), or another susceptible cultivar ('Juliet')..

Figure 3.1. Planting design for the paired-plant experiment..........................54

Figure 3.2. Example HPLC chromatogram. 57 
Figure 3.3. Salicylic acid (SA) standard curve

Figure 3.4. Increase in salicylic acid (SA) in early blight resistant cultivar 'Juliet' and heirloom cultivar 'Brandywine' after inoculation with $A$. solani...........59

Figure 3.5. Linear regression of early blight AUDPC in the field on salicylic acid (SA) basal levels in 16 tomato cultivars .62

Figure 3.6. Linear regression of early blight AUDPC in the field on salicylic acid (SA) 72 hrs after inoculation with Alternaria solani in 16 tomato cultivars 63

Figure 3.7. Linear regression of early blight AUDPC in the field on the increase in salicylic acid (SA) levels $72 \mathrm{hrs}$ after inoculation with Alternaria solani in

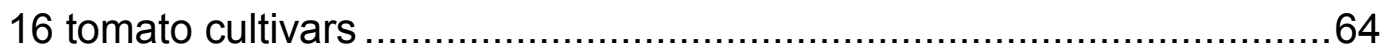

Figure A.1. Hyphal salicylic acid (SA) content. .......................................69 


\section{LIST OF TABLES}

Table

Table 1.1 Early blight disease severity on 16 tomato cultivars in 2001 field trials

Table 1.2 Mean lesion diameter and rate of lesion expansion on four tomato cultivars 2,3 , and 4 weeks after inoculation with $A$. solani. 25

Table 2.1 Greenhouse study treatments

Table 2.2 Mean lesion number (\#) and size of largest lesion $(\mathrm{mm})$ on select leaves of 'Brandywine' (plant 3) planted next to one of three cultivars

Table 2.3 Rate of early blight disease progress ( $r$ ) and Area Under the Disease Progress Curve (AUDPC) on 'Brandywine' in monoculture or intercropped with resistant cultivar 'Juliet' at different positions from the inoculated plant. .45

Table 2.4 Rate of early blight lesion expansion and yield on 'Brandywine' plants in monoculture or intercropped with early blight-resistant cultivar 'Juliet' . 46

Table 2.5 Rate of early blight lesion expansion on tomato cultivar 'Brandywine' in a monoculture or a resistant intercrop at different positions from the inoculated plant. ......46

Table 3.1 Salicylic acid (SA) levels ( $\mathrm{ng} \mathrm{g}^{-1}$ gram leaf) 72 hours after inoculation with $A$. solani in a paired-plant experiment 60

Table 3.2 Area Under the Disease Progress Curve (AUDPC) of 16 cultivars in a field trial and salicylic acid (SA) levels 72 hours after inoculation with Alternaria solani in the greenhouse. 


\section{LITERATURE REVIEW}

Many problems of modern agriculture, such as the overuse of fertilizers and pesticides, are a result of the trend in crop production toward homogeneous crop genotypes for certain agricultural areas (Browning and Frey, 1969). In fact, monoculture is presently the dominant form of crop management (Zhu et al., 2000). Until about 100 years ago, monoculture was practiced only at the species level with crops such as wheat, maize and rice prevailing in specific climatic regions. Since then, the numbers of species, cultivars within species, and the genetic differences within cultivars have been reduced (Wolfe, 2000). Monoculture is convenient because one cultivar is easier to plant, harvest, and market than mixtures of several. Most of the field crops and vegetables grown presently are isoline cultivars, meaning individuals are almost identical phenotypically and genotypically (Leonard and Fry, 1989). Such genetic uniformity could potentially lead to devastation of an entire field by a pathogen (Wolfe, 2000; Leonard and Fry, 1989). In addition, this widespread use of only a few cultivars of each crop increases selection pressure for the rise of pathogens with novel virulence genes.

Browning and Frey (1969) argue that reduction in genetic diversity and widespread use of resistant cultivars eliminate the natural competition and stabilizing tendencies among pathogen strains, giving a selective advantage to new virulent biotypes. The unlimited opportunity for a pathogen to spread in monoculture leads to rapid selection of pathogens that are able to overcome cultivar resistance.

Though the predominant approach to disease control is to continually develop new resistant cultivars and fungicides, this incurs a large cost to the farmer, consumer and the environment (Wolfe, 2000). As a result, many plant pathologists are looking for alternatives to the cycles of responding to strains of pathogens that are able to infect previously resistant cultivars. One rapidly growing response to the problems of conventional agricultural is a movement toward "organic" crop production, which emphasizes the use of increased biodiversity and biological interactions to control disease. 


\section{Multilines and Resistant Mixtures}

Mixed cultivar planting is an approach to disease control that contrasts with genetic engineering because it involves an assortment of genotypes and thus results in an increase in genetic diversity as opposed to genetic uniformity (Wolfe, 2000). Inhibiting the spread of pathogen propagules to susceptible plants with the use of resistant cultivars, increasing the distance between susceptible hosts, and activating non-specific defenses after exposure to avirulent pathogens, are explanations for how cultivar mixtures reduce disease (Ngugi et al., 2001). Though the effectiveness of mixed cultivar plantings remains largely unstudied, the mechanism of disease reduction in multilines supports the notion that disease can be reduced in cultivar mixtures.

Multilines were developed in an attempt to limit the ability of pathogen populations to adapt to host resistance (Wilson et al., 2001). Pathogens and their hosts co-evolve, accruing genes that confer mechanisms of virulence or defense, respectively. The loss of genes due to the energy cost associated with their unnecessary expression is called stabilizing selection and is one of the proposed mechanisms behind the effectiveness of multilines. Three different strategies for disease control using multilines have been developed. Each approach uses a mixture of cultivars that are similar in production traits such as height and maturity (for harvest convenience), but that differ in the expression of resistance.

The first method, "clean crop" multilines, was developed by Borlaug and practiced in Columbia and India to control wheat rusts. Six to eight different cultivars are used, each resistant to all of the races of the pathogen(s) to be controlled. Using this "completely resistant" approach, when a new pathogenic race appears, the grower should replace the susceptible cultivar with a new resistant cultivar. With this system, the multiline should be disease-free (Borlaug, 1958).

The next method, developed by Browning and Frey (1969) at lowa State, is known as "dirty crop" multilining. Eight to ten cultivars carrying different single 
specific resistance genes are used to control all races of the pathogen. Each cultivar is not resistant to all races of the pathogen, as in the clean crop method, but the combination of cultivars covers all known resistance genes against a pathogen. Theoretically, different pathogen races survive in the multiline population, but competition between various races stabilizes the composition of the population. Each host carries a single resistance gene, so there is limited pressure to select races able to overcome multiple resistance genes. In theory, the pathogen population will be composed of simple races with only one or a few virulence genes. The non-host plants serve as "propagule traps" that slow down the spread of the disease. Super-virulent races would not evolve because each host only carries a single resistance gene, based on the premise that stabilizing selection is active (Van der Plank, 1968). Though such multilines contain some disease, the diversity of resistance genes is expected to slow down epidemics and the evolutionary flexibility of the pathogen.

The third approach to multiline disease reduction was developed by Wolfe (1985) to control powdery mildew in barley. As with "dirty crop" multilines, the "simple cultivar" approach uses a mix of different cultivars with different resistance genes as spore traps for different races of the mildew pathogen. The mixture is made up of two to five cultivars compared with eight to twelve in the "dirty crop" approach. Both methods assume that unnecessary virulence in the pathogen is selected against and the development of complex races is curbed, however, Wolfe does not believe that the development of complex races is completely halted. Instead, when complex races develop, the grower should introduce a new mixture to keep the pathogen population in constant equilibrium through stabilizing selection. Wolfe's approach also requires that changes in virulence of the pathogen must be continually monitored in order to introduce new resistant cultivars into the mixture.

The potential for disease reduction through the use of multilines has been discussed for many years, however the effectiveness of these strategies remains controversial and few experiments have been conducted to discriminate among methods (Leonard and Fry, 1989). The efficacy of multilines for disease 
reduction has largely been documented with aerial diseases and grain crops where auto-infection is limited. In addition, many critics claim that multilines are breeding grounds for super-virulent pathogen races as opposed to methods for reducing disease (Browning and Frey, 1969). Therefore, the practicality and effectiveness of multilines for broad-spectrum disease control on many crops remains disputed (Leonard and Fry, 1989).

Intercropping with resistant cultivars has been shown to reduce the spread of disease to susceptible cultivars by similar mechanisms to those in multilines. This practice involves planting two different plant types (different cultivars or species) into the same field, as opposed to a multiline that intercrops plants of the same cultivar with different resistance genes.

In China, intercropping a susceptible rice cultivar with a resistant one across thousands of farms reduced the incidence and severity of rice blast (caused by Magnaporthe grisea) on the susceptible cultivar to levels that no fungicide applications were required (Zhu et al., 2000). In this system, the susceptible rice cultivar produced $89 \%$ greater yield and had $94 \%$ less blast severity when planted with the resistant cultivar compared to the susceptible monoculture. Glutinous, or "sticky" rice has a higher market value than nonglutinous rice. However, glutinous rice is more susceptible to rice blast, therefore $98 \%$ of the rice grown is non-glutinous monocultures. Zhu et al. were able to survey 3,342 ha. of rice planted either in glutinous monoculture, hybrid nonglutinous monoculture, or a mixture of the two (with one glutinous row every four non-glutinous rows). Glutinous monoculture plots averaged $20 \%$ rice blast severity compared with only $1 \%$ when interplanted with non-glutinous rice. Mixed cultivar plots also produced more grain hectare ${ }^{-1}$ than either monoculture.

Kousik and Ritchie (1996) report that mixed cultivar plantings of bell pepper, Capsicum annum, resulted in a decrease in bacterial spot severity (caused by Xanthomonas campestris) on susceptible cultivars. In this experiment, two cultivars of $C$. annum, 'Camelot' (susceptible to all races of the pathogen) and ' $X 3 R$ ' (resistant) were planted in three different field 
arrangements. Reduced disease and increased yield were observed on 'Camelot' when interplanted with 'X3R' as compared to a monoculture.

In another study, sorghum anthracnose (caused by Colletotrichum sublineolum) and leaf blight (caused by Exserohilum turcicum) were reduced on susceptible cultivars of sorghum when intercropped with a resistant cultivar and maize (Ngugi et al., 2001). In both the intraspecific and interspecific mixtures, the time when disease was first observed and the rate of disease progress was reduced on the susceptible cultivar. Intra-row mixtures as opposed to inter-row mixtures were more effective in reducing rates of disease because the intra-row arrangements always had a smaller area of susceptible tissue. Crop mixtures also had a greater effect on reducing E. turcicum than C. sublineolum due to differences in pathogen dispersal. Spores of the former are wind-dispersed, whereas those of the later are splash-borne. Mixtures are less effective in controlling diseases dispersed by splashed rain because auto-infection is high and is independent of the presence of other plants in the mixture (Mundt and Leonard, 1986, and Wolfe, 1985.)

Finally, potato late blight (caused by Phytophthora infestans) was reduced on susceptible cultivar 'Red LaSoda' when intercropped with resistant cultivar 'A90586-11' (Garrett and Mundt, 2000). The resistant/susceptible mixtures produced less disease than the amount predicted according to each cultivar's average in monoculture and its proportion in the mixture. These results suggest another mechanism may be involved in disease reduction in mixtures beyond the reduction in the amount of susceptible plant material.

\section{Mechanisms for Disease Reduction in Cultivar Mixtures}

Throughout history, mixtures of wheat were considered more productive than single cultivars (Darwin, 1872). However, mechanisms for this phenomenon were not elucidated. Cultivar mixtures were hypothesized to restrict the spread of pathogens because they contain less susceptible plant material (Burdon and Chilvers, 1976, Wolfe, 1985). Other studies suggested additional mechanisms 
beyond the "physical barriers" created by resistant cultivars (Calonnec et al., 1996; Chin and Wolfe, 1984; Lannou et al., 1995; Zhu et al., 2000).

In resistant cultivars, every cell has the ability to change metabolism in response to pathogen exposure. The result is death of host cells immediately surrounding the lesion (the hypersensitive response (HR)), as well as smaller and fewer subsequent lesions. The HR causes infected cells to lose membrane integrity and to accumulate brown compounds as a result of phenolic oxidation by peroxide and phenyloxidase enzymes (Goodman and Novacky, 1994). The HR may be triggered by a dominant gene that is present, but not expressed, in cells of resistant cultivars that are uninfected. Therefore, a cultivar susceptible to a particular pathogen does not have the genetic potential to initiate an HR in response. However, this same cultivar may be resistant to a different pathogen, initiate a $\mathrm{HR}$, and then show enhanced resistance against the original virulent pathogen. This induced resistance, termed systemic acquired resistance (SAR), is non-specific, effective against viruses, bacteria, fungi and nematodes, and can last for several weeks. SAR is triggered by inducing the host HR. For example, resistance to a virulent race of Melampsora lini is induced in flax, Linum usitatissimum, by inoculation of the leaves with an avirulent race (Littlefield, 1969). Similar experiments have been done inducing resistance in several pathosystems indicating that SAR is a widepread phenomenon (Agrawal et al., 2000). In each case, an avirulent pathogen had a dominant gene whose product was recognized to induce the host HR.

Cultivar mixtures can reduce disease by pathogens such as powdery mildew (Erysiphe graminis), wheat brown rust (Puccinia graminis) and wheat yellow rust (Puccinia striiformis) because the diversity of the pathogen population is more likely to trigger this broad spectrum, enhanced resistance in plants (Chin and Wolf, 1984; Brophy and Mundt, 1991; de Vallavielle-Pope et al., 1990). Zhu et al. (2000) hypothesized that induced resistance may contribute to the reduction in rice blast severity on glutinous rice cultivars planted in mixtures. Evidence for this induced resistance is that resistant cultivars have less disease when planted in mixtures compared to monoculture. Some saprophytic 
organisms, as well as plant growth promoting bacteria, have the ability to activate the host gene for HR and initiate induced resistance as well (Baker and Cook, 1974; Agrawal et al., 2000, van Loon et al., 1998). Volatile defense-associated chemicals (such as ethylene, methyl ester jasmonic acid (MeJA) and methylsalicylic acid (MeSA)) expressed in the resistant host may be sensed in a susceptible host within close proximities (Farmer and Ryan, 1990; and Shulaev et al., 1997).

Resistance to a pathogen is a result of either constitutive defenses or the activation of a defense response after pathogen recognition at the cellular level. Few examples of constitutive defenses against pathogens are known, but the majority of resistance is a combination of several active responses to a pathogen post-infection (Agrawal et al., 2000). Monogenic resistance (controlled by a single gene) is specific for a given pathogen strain, whereas polygenic resistance is effective against different strains of a pathogen. Polygenic resistance is responsible for resistance to less specialized parasites, such as Phytophthora spp. or Rhizoctonia spp. (Baker and Cook, 1974). Host species may vary considerably in the degree of expressed polygenic resistance. Van der Plank (1968) refers to polygenic resistance as involving genes that "regulate ordinary processes", which is supported by evidence that stressed plants are more susceptible to disease.

Plants that are resistant to a pathogen often have a coordinated expression of many defense responses. Salicylic acid (SA), a simple phenolic compound, has been shown to be an important signaling molecule that activates multiple plant defense responses against a pathogen. SA was first found to be involved in disease resistance when external application induced resistance to TMV in tobacco (Malamay et al., 1990). Increases in SA to $30-600 \mathrm{ng} \mathrm{g}^{-1}$ of leaf tissue occur just prior to the initiation of SAR. The induction of SAR occurs in most, if not all, plant species and triggers a broad-spectrum resistance in the host systemic tissue (Agrawal et al., 2000). Infection by a pathogen induces an unidentified chemical that promotes the production of SA as early as 14 hours locally and 48 hours systemically (Vernooij et al., 1994). SA and CGA-245704 
(benzo[1,2,3]thiadiazole-7-carbothioc acid S-methyl ester) are involved in activating the expression of additional defense related proteins and enzymes. Once activated by the pathogen elicitor, the host defense mechanism remains active, even if the inducer is degraded. Consequently, initiation of SAR to a single pathogen could provide protection for many weeks (Agrawal et al., 2000).

SA functions in initiating the defense response by inhibiting catalase activity, thereby increasing levels of $\mathrm{H}_{2} \mathrm{O}_{2}$ and related active oxygen species (Conrath et al., 1995). However, because of the phytotoxic affects associated with these oxidative compounds, SA is rapidly converted to glucosyl salicylate (GS). A predominant, stable conjugate is SA 2-O- $\beta$-D-glucoside (SAG), which accumulates over time provides a slow-release form of SA (Lee and Raskin, 1999). SAG may account for effectiveness of SAR over long periods of time. SA also is converted to methyl-salicylic acid (MeSA), a volatile compound, which could act as the signal between neighboring plants to induce resistance in otherwise susceptible cultivars. For example, after inoculation with TMV, eight resistant tobacco plants (each producing $23 \mu \mathrm{g}_{\text {of }} \mathrm{MeSA}$ day $^{-1}$ ) triggered SAR in neighboring non-inoculated tobacco plants in a growth chamber (Shulaev et al. 1997).

Another volatile defense compound produced in some hosts is methyl jasmonic acid (MeJA). JA is a ubiquitous signaling molecule found in over 160 plant families including angiosperms and gymnosperms, as well as algae (Sembdner and Parthier, 1993). In 1990 it was discovered that MeJA, volatilized from Artemesia, triggered increased gene expression and a defense response in adjacent tomato plants (Farmer and Ryan, 1990). The level of JA increases in response to wounding, drought, herbivory, microbial cell wall elicitors, and the signaling peptide, systemin (Agrawal et al., 2000). The various defense genes that JA can induce include PR proteins and enzymes involved in synthesis of phytoalexins, such as alkaloids, flavanoids, terpenoids, and anthraquinones. However, JA's role differs among various plant species. Perhaps the most significant role that JA plays in plant defense is its ability to inhibit the expression of genes involved in photosynthesis and ribosome inactivating proteins after 
pathogen invasion. This leads to localized cell death, which blocks further invasion of the pathogen (Reinbothe et al., 1994). Although JA has been shown to be involved in defense against pathogens, its involvement in resistance to herbivory is better documented (Agrawal et al., 2000).

Another mechanism for increased resistance in susceptible plants intercropped with resistant plants may be the spread of various secondary compounds involved in triggering disease resistance through mycorrhizal fungi. Though there is no evidence to support that plant compounds move through arbuscular mycorrhizal fungal hyphae and are taken in by neighboring plants, the hyphae are actively taking up plant sugars and serve as a sink for phloem constituents, such as SA (Morton, personnal communication).

The mechanism of disease reduction due to intercropping with resistant cultivars can be determined when disease is initiated from a single point. If disease is reduced because of lower volume of susceptible plant material, then the onset of symptoms on the susceptible cultivars should be delayed due to the blockage of spores by the resistant cultivar, and the number of lesions will be lower due to reduced inoculum, but the size of individual lesions that develop will be identical to those in monoculture. If resistance is being induced in susceptible cultivars intercropped with resistant cultivars, then the lesion size on the susceptible cultivars may be smaller when intercropped compared to the monoculture. There also could be a higher frequency of failed infections on intercropped susceptible cultivars that can be observed under the microscope (Hammerschmidt and Nicholson, 2000).

Regardless of the mechanism, research shows that the net result of mixed cultivars is a reduction in disease incidence and severity. Lannou et al. (1994) hypothesized that the most likely reason is an increase in the diversity of the pathogen population over several seasons, which slows the adaptation of the pathogen to the mixture. This is due to increased competition between pathogen genotypes that are specific to certain cultivars in the mixture and those that are less specialized and can infect many cultivars. Rotating fields with different mixed cultivars each year should slow adaptation of the pathogen (Wolfe, 2000). 


\section{Justification for Resistant Mixtures}

The planting of susceptible cultivars when resistant cultivars are available may appear counter intuitive. However, there are several reasons for this practice. First, planting crop mixtures increases the genetic diversity of the host within the field. Pressure on the pathogen to overcome host resistance through mutation is reduced. An increase in the genetic diversity of the host also reduces the likelihood of an epidemic. Second, crop mixtures would allow growers to plant cultivars that are otherwise avoided because they are highly susceptible to disease. For example, many small growers praise the heirloom tomato cultivar 'Brandywine' for its size, color and flavor, though it is very susceptible to disease. The ability to grow 'heirloom' cultivars economically would preserve rare plants whose germ lines may become useful in the future for developing new cultivars. Finally, crop mixtures allow various genes to be expressed within the same field, without the high costs that result from genetically engineered crops.

\section{Why Resistant Mixtures Are Not Widely Used}

If the mixture approach has the advantage of reducing disease on susceptible cultivars, why is it not more widely used? One reason is that mixtures may be harder to harvest due to physical differences in the crops such as height or maturation time, raising concerns about quality of harvest. In practice, these concerns can be avoided, as demonstrated by Zhu et al. (2000) when cultivars can be grown in separate rows. In areas where harvesting is done by hand, such as rice in the Yunnan Province in China where Zhu's study took place, cultivars with different qualities can be easily separated. The spread of cultivar mixtures among organic farms may be facilitated by the fact that harvesting by hand is a common practice. 


\section{Conclusions and Recommendations for Further Research}

The 'Green Revolution' has dramatically increased crop productivity, which has helped to feed over six billion people throughout the world. Yet, despite our agricultural advances, many problems have persisted. These include increased chemical dependence linked to ground water pollution (Abelson, 1990), loss of native soil microbiota (Olsson and Gerhardson, 1992) and a loss of crop genetic diversity. Mixed cultivar planting has been shown to help combat these problems and to increase yields (Garrett and Mundt, 2000; Kousik and Ritchie, 1996; Zhu et al., 2000). Though it may be argued that mixed plantings only work on small scales where harvesting is done by hand, the approach may be appropriate on a large scale for certain crops. For example, in the Pacific Northwestern United States, wheat (Triticum aestivum) mixtures are grown using highly mechanized practices (Garrett and Mundt, 1999). The most practical and environmentally sound way to control disease is to broaden the genetic base of crops by searching for many sources of genetic resistance in nature (Barksdale, 1969). We can potentially use these resistant cultivars to reduce the amount of disease that infects landrace and heirloom cultivars that are valued by growers for their local adaptations and fruit quality.

There may be other benefits gained from crop mixtures in addition to disease resistance. This includes reduction of insect pests, increased soil biodiversity, and extended harvest throughout the season. Crop mixtures are not the only means to prevent the overuse of chemicals and the loss of biodiversity, but they could be a step in the right direction. In addition, there are several crops in which intercropping may not be an option due to the limited availability of different cultivars. However, we need to understand more about the cultivar mixtures that work best for different purposes, and whether there are specific cultivars that work better in mixtures than others (Wolfe, 2000). Little research on the possible effects of intercropping with different species has been done and much remains to be studied in this area. 


\section{STUDY OBJECTIVES}

The purpose of this research was to:

1) Determine or verify resistance to Alternaria solani (early blight) and Meloidogyne incognita (root knot disease) in tomato cultivars 'Juliet', 'Celebrity', and 'Brandywine' for their use in subsequent intercropping experiments.

2) Quantify early blight and root knot disease incidence and severity on susceptible tomato plants intercropped with resistant cultivars and determine the effect on yield.

3) Measure early blight lesion expansion on susceptible cultivars when they are intercropped with resistant cultivars and compare that to lesion expansion in a susceptible monoculture.

4) Investigate potential mechanisms of increased resistance in the susceptible cultivar, if observed.

5) Determine field resistance to Alternaria solani (early blight) in 16 tomato cultivars and evaluate its correlation with salicylic acid production 72 hours after inoculation in the greenhouse. 


\section{HYPOTHESES TESTED}

1) 'Brandywine' is susceptible to Alternaria solani (early blight) and Meloidogyne incognita (root knot disease), 'Celebrity' is resistant to $M$. incognita, and 'Juliet' is resistant to $A$. solani.

2) The rate of spread of Alterniaria solani (early blight) and Meloidogyne incognita (root knot disease) to susceptible plants is reduced when 'Brandywine' is intercropped with resistant cultivars compared to 'Brandywine' monoculture.

2) 'Brandywine' has increased resistance to early blight and in the presence of resistant cultivar 'Juliet'.

3) Increased resistance in 'Brandywine' is due to an induced response initiated by neighboring resistant plants, in addition to a reduction in susceptible plants.

4) The concentration of salicylic acid in 'Brandywine' leaves is higher when grown with 'Juliet' compared with 'Brandywine' leaves grown alone.

5) The level of salicylic acid produced by a tomato cultivar 72 hours after it is inoculated with $A$. solani is proportional to field resistance to early blight. 


\section{CHAPTER 1}

\section{Determination of resistance to Alternaria solani and Meloidogyne incognita in tomato cultivars.}

\section{Introduction}

The trend toward greater genetic uniformity and the reduction in cultivar diversity in crop production increases problems associated with disease control (Wolfe, 2000; Leonard and Fry, 1989). Long term stability in food security can be attained by the use of many crops and many different cultivars. Novel resistance genes are often found in rare varieties and wild relatives of crop species and there is a great need for the discovery of new resistance genes as pathogens continue to evolve ways to overcome the resistance in widely grown cultivars.

Early blight, caused by Alternaria solani, is a defoliating disease on tomatoes and was chosen for this study because control is accomplished primarily through chemical fungicides (Jones and Jones, 1991). There is no commercial tomato cultivar that has sufficient levels of resistance to $A$. solani due to the complex patterns of inheritance and the lack of single-gene resistance (Rotem, 1999). Therefore, screening rare varieties and wild tomato relatives for early blight resistance is greatly needed. Methods of screening for resistance to early blight include assessing foliar phytotoxicity to culture filtrates of $A$. solani (Maiero et al., 1991) and measuring lesion expansion on inoculated detached leaflets in moist chambers (Locke, 1948). However, the most effective method is in the field.

Growers have problems with early blight control. In organic crop production, where synthetic fungicides are not allowed, growers often rely on cultivar resistance as a means for disease control. In addition, organic growers often grow rare 'heirloom' varieties for their unique appearance or taste, however resistance to $A$. solani is not well characterized in these varieties. Cultivars that are listed as 'resistant' in catalogs, such as 'Juliet' and 'Mountain Supreme', may still show symptoms of early blight, but lesion expansion is slower, or spore 
production may be inhibited. In addition, many of the more rare varieties listed in catalogs have not been screened for resistance.

Alternaria solani is a deuteromycete fungus causing target-like lesions on tomato, potato and eggplant, and producing spores that are dispersed by wind and splashed rain. Early blight is the most common tomato leaf spot disease in the Central and Atlantic states. The lack of resistant cultivars requires organic growers to rely on frequent applications of copper or sulfur to control the disease. The disadvantages with these methods of control include damage on fruit and foliage as well as copper build-up in the soil. Therefore, growers are looking for alternatives, such as resistant cultivars, for control of early blight on tomatoes.

In 1942, the U.S. Breeding Laboratory, in Charleston, South Carolina, tested hundreds of wild tomato species for resistance to $A$. solani (Rotem, 2000). The basis for commercial cultivar resistance to $A$. solani comes mainly from crossing $L$. esculentum with $L$. pimpinellifolium, $L$. hirsutum, and $L$. peruvianum. Unfortunately, resistance in the stem has a higher coefficient of heritabiltiy than resistance in the leaves (Stancheva, 1991). Difficulty in identification and selection of the resistance genes is due to their interaction with genes that affect plant morphology, growth patterns, and resistance to other diseases (Rotem, 2000).

Root knot nematodes (Meloidogyne spp.) are obligate endoparasites on a number of crop plants and cause low yield, stunted growth, and increased susceptibility to other pathogens. The disease is characterized by the presence of galls on infected roots. Single gene resistance to root knot nematode was identified in $L$. peruvianum, however this resistance breaks down at temperatures above $32^{\circ} \mathrm{C}$. An interspecific hybrid was created using embryo rescue and this plant is still the only source of root knot nematode resistance (Williamson, 1998). The resistance gene from this hybrid was identified and called the tomato $\mathrm{Mi}$ gene, which confers resistance to three species of nematode ( $M$. incognita, $M$. javanica, and M. arenaria) and to the potato aphid, Macrosiphum euphorbiae (Rossi et al., 1998). 
In this study, 16 tomato cultivars were tested for resistance to $A$. solani in the field: 'Arkansas Traveler', 'Brandywine', 'Celebrity', 'Daybreak', 'Green Zebra', 'Johnny's 361', 'Juliet', 'Matt's Wild Cherry', 'Prudence Purple', 'Red Currant', 'Striped German', 'Sungold', 'Valley Girl', '99197', '99199', ‘99203'. In addition, resistance to $A$. solani and $M$. incognita, was evaluated in the greenhouse on three cultivars and the results were used for designing subsequent intercropping studies. Resistance to $A$. solani and $M$. incognita on these cultivars was compared to susceptible controls, cultivars 'Daybreak' and 'Rutgers', respectively.

\section{Materials and Methods}

Field Cultivar Trial

Plots consisting of four tomato plants of each cultivar were established at the WVU Organic Research Farm. Plots were arranged in a randomized complete block design with five replicates. Six-week-old seedlings of 16 tomato cultivars (Table 1.1) were transplanted on May 27, 2001 into Dormant and Guernsey silt loam soil. Plants were spaced $90 \mathrm{~cm}$ apart, both within and between rows. Approximately $1.4 \mathrm{~kg}$ dry weight of composted cow manure was placed in each planting hole at transplant. Plants were staked with $1.3 \mathrm{~m}$ bamboo poles and mulched with newspaper and hay. Inoculum consisted of naturally occurring wind-borne spores of $A$. solani. Wet, humid weather throughout the season made conditions favorable for early blight progression so inoculum density was adequate for disease development. Disease was measured July 13 and at 7-day intervals thereafter until frost on October 5 . The proportion of foliage with symptoms of early blight was visually rated on each plant at each monitoring date. Percent symptomatic tissue was plotted over time and area under the disease progress curve (AUDPC) was determined at the end of the season. AUDPC values were used to compare cultivar resistance. 


\section{Greenhouse Study}

Twenty-four seedlings of 'Juliet', 'Brandywine', and 'Celebrity' were transplanted into six-cell packs (Brighton By-Products, New Brighton, PA) with Sunshine Mix \#1 potting soil (Brighton By-Products, New Brighton, PA) 2 weeks after seeding. Cultivar 'Rutgers' was used as a susceptible control for screening for resistance to root knot. Cultivar 'Daybreak' was used as a susceptible control for screening for resistance to early blight. Six replicates of four treatments included a non-inoculated control, spray-inoculation with a 20,000 spore $\mathrm{ml}^{-1}$ suspension of $A$. solani, and inoculation with $M$. incognita at 300 or 3000 eggs plant $^{-1}$. Greenhouse temperatures were maintained between $20-30^{\circ} \mathrm{C}$ throughout the experiment. Plants were fertilized with 100 ppm 20-10-20 as needed.

\section{Pathogen Inoculum}

Alternaria solani. Samples of tomato leaves infected with $A$. solani were collected from the WVU Organic Research Farm. Sections from margins of lesions were surface sterilized in $10 \%$ Clorox for 30 seconds and placed on V8 agar plates. Identification of the pathogen was verified morphologically.

A pure culture of $A$. solani was maintained in the lab under fluorescent lights with 8 hours of darkness each day. Two-week-old fungal colony surfaces on V8 agar were gently scraped to disrupt hyphae (Yan and Reddy, 1999). Spores were collected 24 hours later by rinsing the agar surface with distilled water and a 20,000-spore $\mathrm{ml}^{-1}$ suspension was sprayed onto leaves. Plants were placed on a mist bed for 24 hours after inoculation to provide conditions for spore germination and penetration.

Meloidogyne incognita. M. incognita eggs were obtained from 3-month-old cultures that were established from single egg masses and maintained the WVU greenhouse on 'Rutgers' tomato plants. Eggs were extracted by shaking roots in $1 \% \mathrm{NaOCl}$ for 5 minutes and a $27-\mu \mathrm{m}$ pore sieve was used to collect the eggs (Hussey and Barker, 1973). Eggs were rinsed with tap water for 2 minutes, placed in distilled water and counted to determine number of eggs per milliliter. 
The desired egg concentrations were added to the experimental plants the same day.

\section{Disease Measurements}

Root Knot Disease. Eight weeks after inoculation with M. incognita, the root mass was dipped into water and the soil was rinsed from the roots. The number of galls on $1 \mathrm{~g}$ of roots was counted under a light microscope and then eggs were extracted from roots as above. Total number of eggs recovered from each root system was counted and the final population $\left(P_{f}\right)$ was determined. Cultivar resistance was determined by dividing the number of eggs recovered by the number of eggs inoculated (Reproductive Index $(R)=P_{f} /\left(P_{i}+1\right)$ ). One was added to the initial population in order to account for control treatments where the inoculum level was zero. Cultivar tolerance was determined by measuring shoot dry weight.

Early Blight. For plants inoculated with A. solani, average lesion size was determined by measuring the diameter of all the lesions present on the third and fifth leaf on the main stem from the bottom of the plant. Lesions were measured once a week for 3 weeks beginning 2 weeks after spray inoculation with a 20,000 spore $\mathrm{ml}^{-1}$ solution. At the end of the experiment, the third and fifth leaves were excised and lesions were examined for spore production.

Statistical Analysis. For the field trial, AUDPC was calculated for each plant of the 20 replicates among the 16 tomato cultivars. The block effect was not statistically significant, therefore data were analyzed using a completely randomized one-way ANOVA. Tukey's HSD $(P=0.05)$ was used to compare mean AUDPC among cultivars. For the greenhouse trial, number of $M$. incognita eggs recovered were log transformed to reduce heterogeneity of variances among treatments. Two-way ANOVA and Tukey's HSD means comparison ( $P=$ 0.05 ) were used to compare the log transformed final egg populations, number of galls $\mathrm{g}^{-1}$ of root, and shoot dry weight among treatments. 


\section{Results}

\section{Field Cultivar Trial}

Total lesion area due to early blight increased linearly throughout the season. An outbreak of late blight was observed on August 24. Disease severity data collected after September 14 were omitted from analyses due to the inability to distinguish between the two foliar diseases after that date. Early blight disease severity was highest on 'Daybreak' and lowest on 'Matt's Wild Cherry', '99199', 'Red Currant', '99197', '99203', and 'Juliet'. 'Sungold' and 'Prudence Purple', an heirloom cultivar, had intermediate levels of resistance (Table 1.1). By the first frost on October 7 , the only cultivar with remaining green foliage was 'Matt's Wild Cherry' which appeared to be resistant to both late blight and early blight.

\section{Greenhouse Study}

Root Knot Screen. The reproductive indices for M. incognita on 'Brandywine', 'Celebrity', and 'Juliet' did not differ significantly (Figure 1.1). 'Rutgers' was the best host and had a significantly greater reproductive index when inoculated at the lower level compared to other cultivars.

'Celebrity', had significantly lower final populations $(P<0.001)$ than 'Rutgers', 'Brandywine', and 'Juliet' at high inoculum levels (Figure 1.2). At low inoculum levels, all four cultivars differed significantly with $P_{f}$ increasing in the order ascending order 'Celebrity', 'Brandywine', 'Juliet', and 'Rutgers'.

The number of galls on 'Juliet' and 'Brandywine' after inoculation at both levels was not significantly different from the susceptible check (Figure 1.3). Galling of 'Celebrity' roots was significantly lower than on the other cultivars, and did not differ significantly from non-inoculated plants. However, five galls $\mathrm{g}^{-1}$ of roots were observed on 'Celebrity' when inoculated with 3000 eggs.

Some level of tolerance to root knot was observed in 'Brandywine' and 'Celebrity' as indicated by the higher dry shoot weight when inoculated at both levels (Figure 1.4). 
TABLE 1.1. Early blight disease severity on 16 tomato cultivars in 2001 field trials.

\begin{tabular}{ll}
\hline Cultivar & AUDPC \\
\hline Daybreak & 224 a \\
Brandywine & 214 ab \\
Green Zebra & 198 abc \\
Johnnys 361 & 194 abc \\
Valley Girl & 191 abc \\
Striped German & 191 abc \\
Arkansas Traveler & 190 abc \\
Celebrity & 188 abc \\
Sungold & 183 bc \\
Prudence Purple & 162 c \\
Matts Wild Cherry & 123 d \\
99199 & 121 d \\
Red Currant & 119 d \\
99197 & 114 d \\
99203 & 111 d \\
Juliet & 104 d \\
\hline Percentage symptomatic leaf tissue due to A. solani from natural inoculum was measured weekly \\
from July 13 to September 14 on five replicates per cultivar. Area Under the Disease Progress \\
Curve (AUDPC) was determined by summing the percent symptomatic leaf tissue values from \\
each monitoring date over the season. Means followed by the same letter do not differ \\
significantly ( $<$ 0.05) according to Tukey's HSD. \\
\end{tabular}




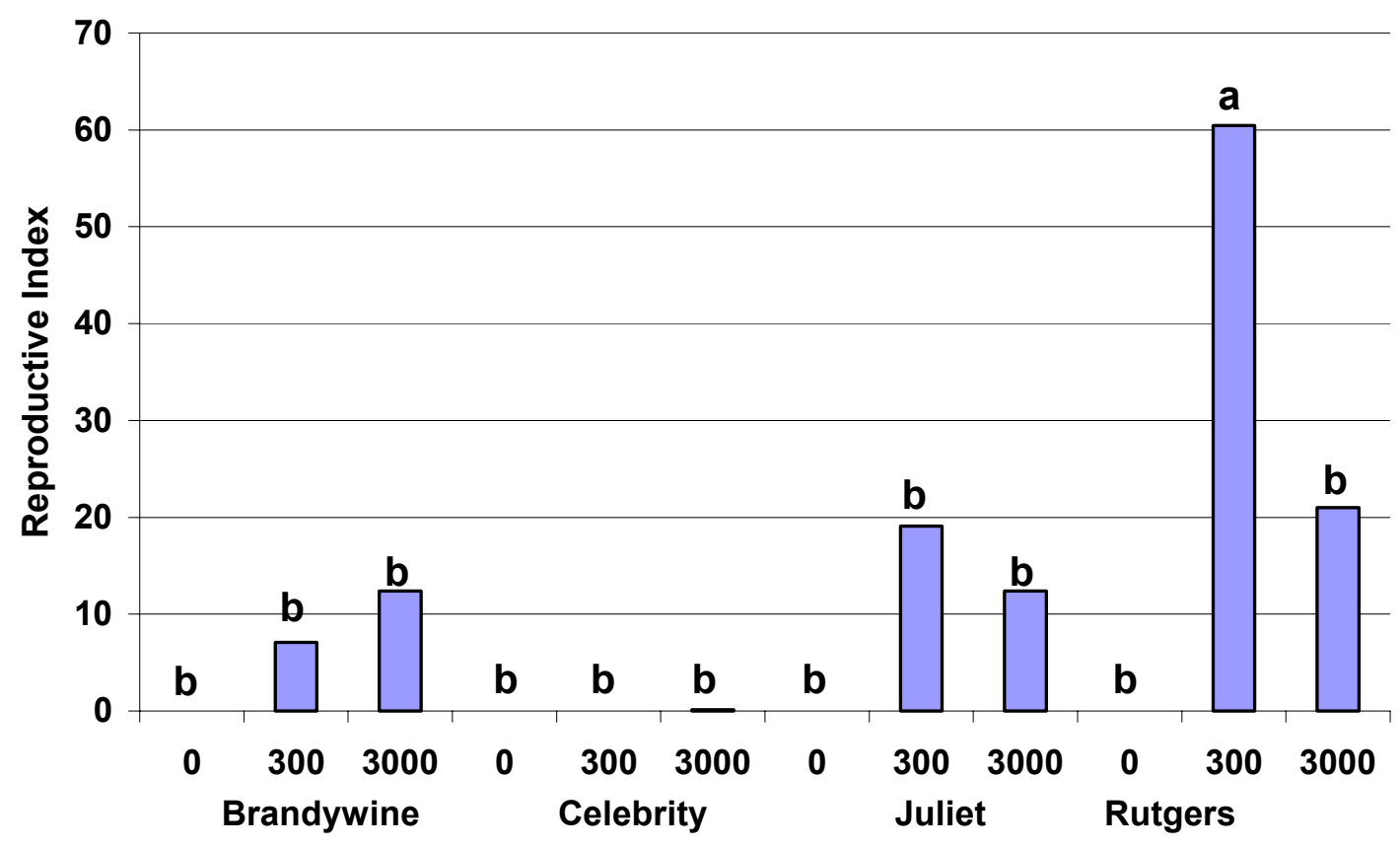

Figure 1.1. Reproductive index $(\mathrm{R}) 8$ weeks after inoculation of four tomato cultivars with $M$. incognita with 0,300 , or 3000 eggs per plant. $\left(R=\left(\#\right.\right.$ of eggs recovered $\left.\left(P_{f}\right)\right) /(\#$ of eggs inoculated $\left.\left(P_{i}\right)+1\right)$ ). Means followed by the same letter do not differ significantly $(P<0.05)$ according to Tukey's HSD. 


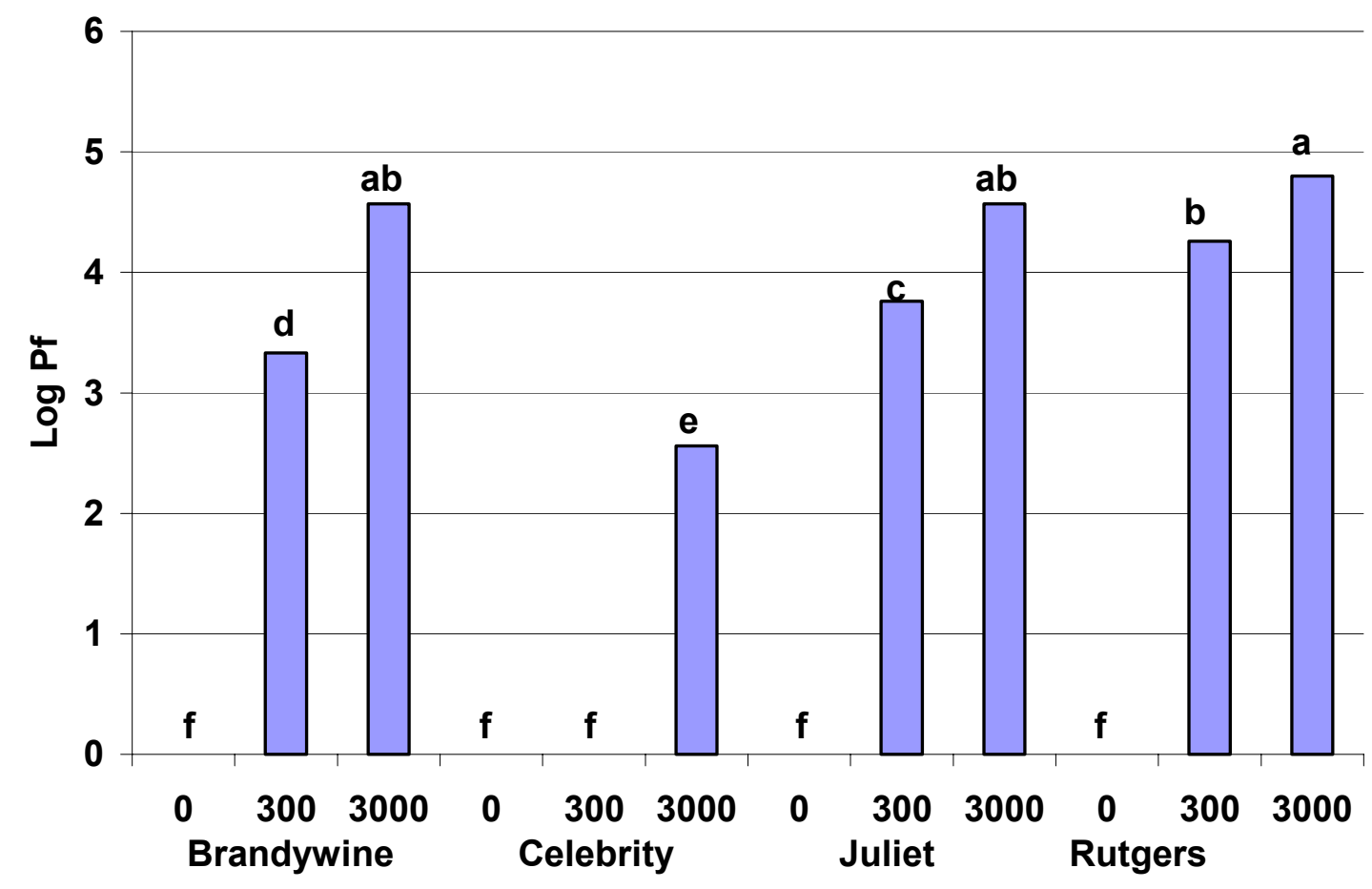

Figure 1.2. Number of $M$. incognita eggs recovered $\left(P_{f}\right)$ on four tomato cultivars 8 weeks after inoculation with 0,300 , or 3000 eggs per plant. Means followed by the same letter do not differ significantly $(P<0.05)$ according to Tukey's HSD. 


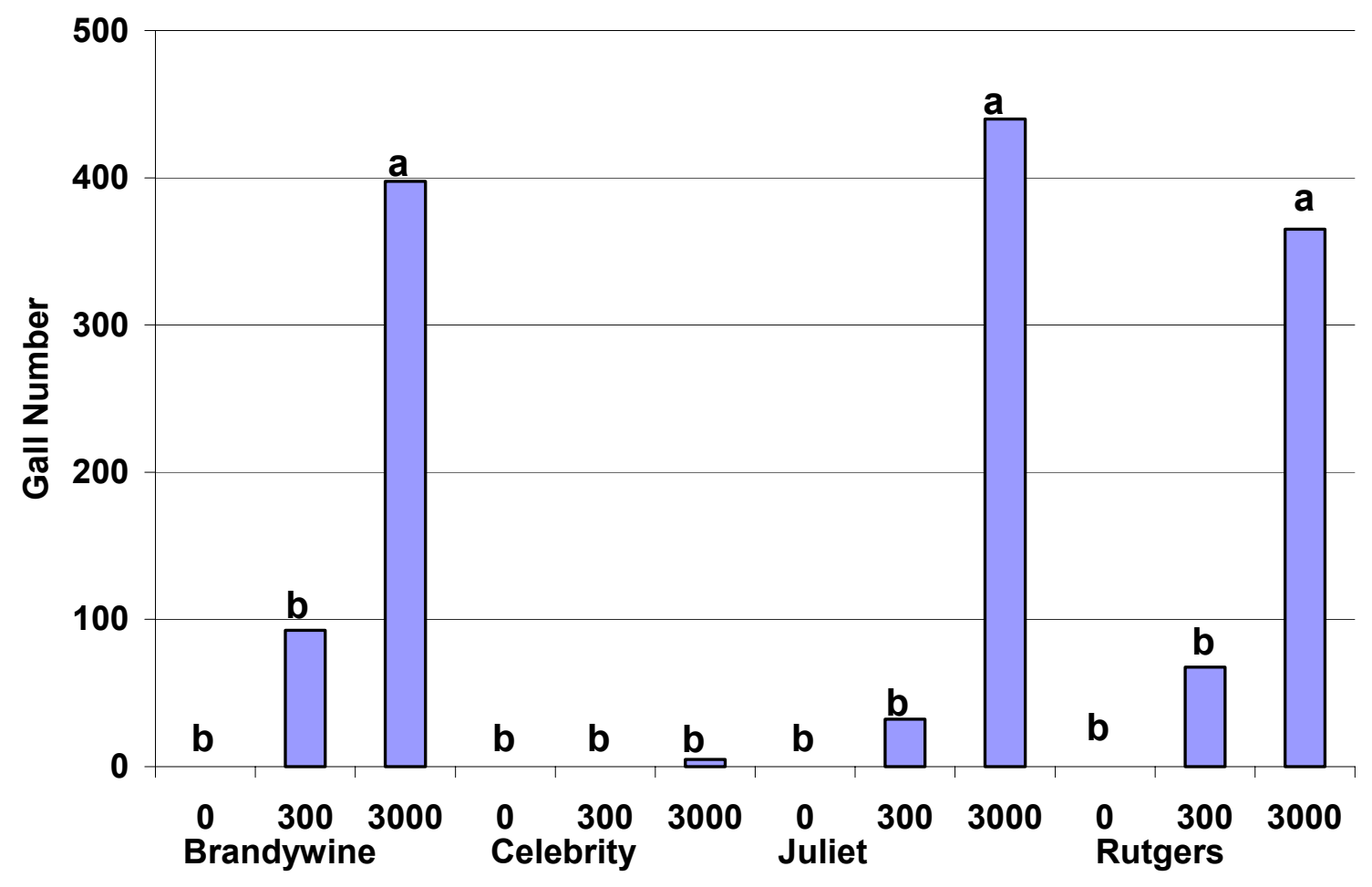

Figure 1.3. Galls per gram of root on four tomato cultivars 8 weeks after inoculation with 0,300 , or $3000 \mathrm{M}$. incognita eggs per plant. Means followed by the same letter do not differ significantly $(P<0.05)$ according to Tukey's HSD. 


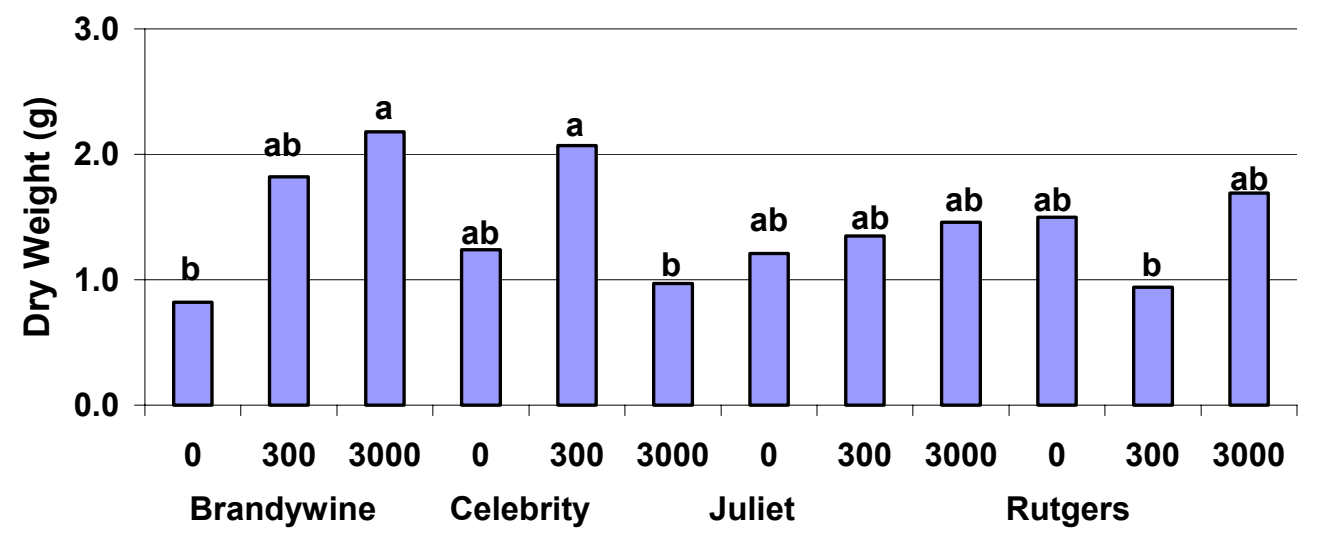

Figure 1.4. Shoot dry weight of four tomato cultivars 8 weeks after inoculation with 0,300 , or 3000 eggs of $M$. incognita per plant. Means followed by the same letter do not differ significantly $(P<0.05)$ according to Tukey's HSD.

\section{Early Blight Screen}

Early blight lesions on 'Juliet' did not exceed $3 \mathrm{~mm}$ in diameter and had the lowest average lesion expansion rate $(R)$. Lesion diameter and expansion rates in 'Brandywine' were not significantly different from the susceptible control 'Daybreak' (Table 1.2). 'Celebrity' had intermediate lesion diameter and expansion rates. Sporulation did not occur on 'Juliet' lesions, though it did on all the other cultivars when lesion size was greater than $5 \mathrm{~mm}$. 
TABLE 1.2. Mean lesion diameter and rate of lesion expansion on four tomato cultivars 2,3 , and 4 weeks after inoculation with $A$. solani.

\begin{tabular}{|c|c|c|c|c|}
\hline \multirow[b]{2}{*}{ Cultivar } & \multicolumn{3}{|c|}{ Lesion Diameter $(\mathrm{mm})$} & \multirow{2}{*}{$\begin{array}{c}\text { Rate of Lesion Expansion } \\
\text { (mm per day) }\end{array}$} \\
\hline & Week 2 & Week 3 & Week 4 & \\
\hline Brandywine & $5.12 \mathrm{a}$ & $10.02 \mathrm{a}$ & $13.1 \mathrm{a}$ & $0.57 \mathrm{a}$ \\
\hline Celebrity & $3.74 \mathrm{~b}$ & $6.72 \mathrm{~b}$ & $8.2 \mathrm{~b}$ & $0.32 \mathrm{~b}$ \\
\hline Daybreak & 5.74 a & $11.14 \mathrm{a}$ & $14.2 \mathrm{a}$ & $0.60 \mathrm{a}$ \\
\hline Juliet & $1.7 \mathrm{c}$ & $1.9 \mathrm{c}$ & $2.1 \mathrm{c}$ & $0.0029 c$ \\
\hline
\end{tabular}

Average lesion diameter was determined by measuring the diameter of all the lesions present on the third and fifth leaf from the bottom of the main stem of the plant. Lesions were measured every 7 days on six replicates per treatment, beginning two weeks after inoculation with a 20,000 spore $\mathrm{ml}^{-1}$. solution. Means followed by the same letter in the same column do not differ significantly $(P<0.05)$ according to Tukey's HSD.

\section{Discussion}

This research evaluated resistance to early blight in different heirloom tomato cultivars in order to identify those resistant to root knot disease and early blight for use in subsequent intercropping experiments. For the field experiment, weather throughout the summer was ideal for the spread of early blight. Natural lesions were spotted in early July and disease progressed linearly.

In general, early-maturing cultivars of tomato are more susceptible to early blight than late maturing cultivars (Rands, 1917), which may explain why 'Daybreak', an early maturing cultivar, was the most susceptible in this field trial (Table 1.1). 'Juliet' was the most resistant cultivar to early blight in the field, and greenhouse studies verified that lesion expansion rates are reduced and spore production does not occur. '99203', '99197', and '99199' are all resistant cultivars (Johnny's Selected Seeds, Albion, ME, personal communication) and were not significantly different from 'Juliet'. 'Matt's Wild Cherry' and 'Red Currant' are cherry cultivars and both had statistically similar levels of resistance as 'Juliet'. Cherry cultivars tend to have higher levels of resistance to early blight 
(Johnny's Selected Seeds, Albion, ME, personal communication) and this study supports this. The only other cherry cultivar was 'Sungold' and it had moderate susceptibility to early blight, though it was statistically different from the most susceptible cultivar, 'Daybreak'.

'Prudence Purple', though statistically different from the most resistant cultivars, had a higher level of resistance compared to the susceptible cultivars. 'Prudence Purple' is an heirloom cultivar that many organic growers claim has tolerance to early blight. This study shows that 'Prudence Purple' has intermediate resistance to early blight and helps to confirm what has been observed over time by various heirloom tomato growers.

Resistance in 'Brandywine' was not statistically different from that in 'Daybreak'. 'Brandywine' is an heirloom cultivar that is known amongst growers to have poor levels of resistance to disease. Increases in susceptibility to $A$. solani occur as the tomato plant ages, therefore early maturing cultivars are more susceptible (Rands, 1917). Since 'Daybreak' was the only early maturing cultivar in the study, its level of resistance to early blight compared to other early maturing cultivars cannot be determined. In addition, 'Johnny's 361', 'Valley Girl', 'Striped German', 'Arkansas Traveler' and 'Celebrity' all are fairly susceptible to early blight and are not statistically different from 'Daybreak'.

The greenhouse study helped to confirm the use of 'Celebrity' as a cultivar resistant to root knot disease and 'Juliet' as a cultivar resistant to early blight in future experiments. As hypothesized, 'Brandywine' and 'Juliet' were both susceptible to root knot disease, however, some resistance to root knot was observed in 'Brandywine'. This was indicated by the higher dry shoot weight compared to susceptible cultivars and lower $P_{f}$ values when inoculated at the low level. However, plants that grow for 8 weeks in 6-cell packs may not give realistic plant growth responses. 'Celebrity' had a high level of resistance to root knot disease at both inoculum levels when compared to the susceptible control. However, some galls were observed on 'Celebrity' when inoculated with 3000 eggs, indicating that resistance may break down at high inoculum levels. 
The early blight screen showed 'Juliet' to be resistant, as indicated by the low lesion expansion rate (Table 1.2). Lesion diameter and expansion rates in 'Brandywine' were not significantly different from the susceptible control, 'Daybreak'.

In conclusion, 'Celebrity' and 'Juliet' are highly resistant to $M$. incognita and $A$. solani, respectively, and therefore are good cultivars to determine the effectiveness of resistant intercrops in reducing root knot disease and early blight on 'Brandywine' in the field. 


\section{CHAPTER 2}

The effects of intercropping with resistant tomato cultivars on the symptom expression of Alternaria solani, and Meloidogyne incognita to tomato cultivar 'Brandywine' in the greenhouse and field.

\section{Introduction}

Intercropping with resistant cultivars has been shown to reduce the spread of disease to susceptible cultivars (Garrett and Mundt, 2000; Kousik and Ritchie, 1996; Ngugi et al., 2001; Zhu et al., 2000). For example, intercropping a susceptible rice cultivar with a resistant one across thousands of farms in China, reduced rice blast (caused by Magnaporthe grisea) on the susceptible cultivar to levels that no fungicide applications were required (Zhu et al., 2000). In this system, the susceptible rice cultivar produced $89 \%$ greater yield and $94 \%$ less blast severity when planted with the resistant cultivar compared to the susceptible monoculture.

Glutinous, or "sticky" rice has a higher market value than non-glutinous rice. However, glutinous rice is more susceptible to rice blast, therefore $98 \%$ of the rice grown is non-glutinous monocultures. Zhu et al. were able to survey 3,342 ha. of rice planted either in glutinous monoculture, hybrid non-glutinous monoculture, or a mixture of the two (with one glutinous row every four nonglutinous rows). Glutinous monoculture plots averaged $20 \%$ rice blast severity compared with only $1 \%$ when interplanted with non-glutinous rice. Mixed cultivar plots also produced more grain hectare ${ }^{-1}$ than either monoculture.

Kousik and Ritchie (1996) report that mixed cultivar plantings of bell pepper, Capsicum annum, resulted in a decrease in bacterial spot severity (caused by Xanthomonas campestris) on susceptible cultivars. In this experiment, two cultivars of $C$. annum, 'Camelot' (susceptible to all races of the pathogen) and 'X3R' (resistant) were planted in three different field arrangements. Reduced disease and increased yield were observed on 'Camelot' when interplanted with 'X3R' as compared to a monoculture. 
In another study, sorghum anthracnose (caused by Colletotrichum sublineolum) and leaf blight (caused by Exserohilum turcicum) were reduced on susceptible cultivars of sorghum when intercropped with a resistant cultivar and maize (Ngugi et al., 2001). In both the intraspecific and interspecific mixtures, the time when disease was first observed and the rate of disease progress was reduced on the susceptible cultivar. Intra-row mixtures as opposed to inter-row mixtures were more effective in reducing rates of disease because the intra-row arrangements always had a smaller area of susceptible tissue. Crop mixtures also had a greater effect on reducing E. turcicum than C. sublineolum due to differences in pathogen dispersal. Spores of the former are wind-dispersed, whereas those of the later are splash-borne. Mixtures are less effective in controlling diseases dispersed by splashed rain because autoinfection is high and is independent of the presence of other plants in the mixture (Mundt and Leonard, 1986, and Wolfe, 1985.)

Finally, potato late blight (caused by Phytophthora infestans) was reduced on susceptible cultivar 'Red LaSoda' when intercropped with resistant cultivar 'A90586-11' (Garrett and Mundt, 2000). The resistant/susceptible mixtures produced less disease than the amount predicted according to each cultivar's average in monoculture and its proportion in the mixture. These results suggest another mechanism may be involved in disease reduction in mixtures beyond the reduction in the amount of susceptible plant material.

The effect of resistant intercropping in reducing disease on susceptible cultivars was tested with two pathogens: $A$. solani (early blight) and $M$. incognita (root knot disease, Chapter 1). The cultivars used in this intercropping study were 'Juliet', which is resistant to early blight, and 'Celebrity', which is resistant to root knot disease (Chapter 1). Though early blight lesions are still produced on 'Juliet' leaves, the plant induces a resistance response upon pathogen recognition, lesion expansion is reduced, and no spores are formed (Chapter 1 and 3). Tomato cultivar 'Celebrity', which contains the Mi gene, was used in plots inoculated with $M$. incognita. 'Brandywine' was used because it is 
susceptible to both $A$. solani and $M$. incognita (Chapter 1 ), but is grown widely by organic farmers and home gardeners for its unique flavor.

\section{Materials and Methods}

\section{Greenhouse Study}

Thirty containers $92 \mathrm{~cm} \times 20 \mathrm{~cm} \times 13 \mathrm{~cm}$ were filled with Lily (fine-loamy, siliceous, semi-active, mesic, typic, hapludult) soil collected from WVU's Organic Research Farm at a location never planted in tomatoes. Field soil was mixed with sand in a 1:1 ratio. Two $\mathrm{cm}$ of gravel lined the bottom of the containers to ensure drainage. Three plants were planted $30 \mathrm{~cm}$ apart in each container. The first plant was cultivar 'Brandywine', the second plant was either 'Brandywine', 'Juliet', or 'Celebrity', and the third plant was another 'Brandywine'. The first plant ('Brandywine') in each container was inoculated with either $A$. solani or $M$. incognita, and disease was measured on the third plant ('Brandywine', Figure 2.1, Table 2.1). Plants were fertilized with 200 ppm Greencare 20-10-20 fertilizer as needed (Brighton By-Products, New Brighton, PA).

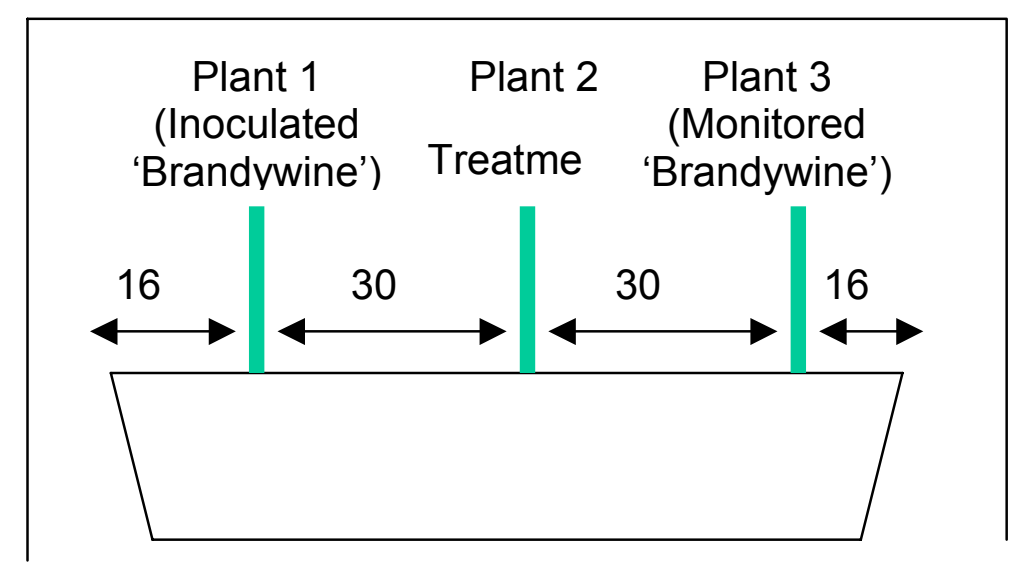

Figure 2.1. Greenhouse study design. There were five replicates of 6 treatments in a randomized complete block design. Plant 1, cultivar 'Brandywine', was inoculated with $M$. incognita or A. solani; Plant 2 was either cultivar 'Brandywine', 'Celebrity' or 'Juliet'; Plant 3, cultivar 'Brandywine' was monitored for root knot disease or early blight for 11 weeks). Containers were surrounded by plastic barriers for increased humidity and to avoid cross contamination between trays. 
TABLE 2.1. Greenhouse study treatments.

\begin{tabular}{llc}
\hline \hline Treatment & Plant 2 & Plant 1 lnoculated with: \\
\hline Monoculture & Brandywine & A. solani \\
Resistant & Juliet & A. solani \\
Susceptible & Celebrity & A. solani \\
Monoculture & Brandywine & M. incognita \\
Susceptible & Juliet & $M$. incognita \\
Resistant & Celebrity & $M$. incognita \\
\hline
\end{tabular}

Plant 1 and 3 were 'Brandywine' in all treatments. Plant 2 was a tomato cultivar that was either resistant or susceptible to the organism with which plant 1 was inoculated.

Five-week-old tomato seedlings were transplanted into the containers (on February 22, 2001) and fertilized as needed. All containers were placed on the floor of the same greenhouse in a randomized complete block design with six treatments and five replicates. Treatments were blocked according to distance from the greenhouse fans to minimize environmental differences within blocks. Plastic barriers surrounded each tray to increase humidity and prevent the spread of inoculum across trays. Plant 1 was inoculated with 3000 eggs of $M$. incognita or sprayed with a 20,000 spore $\mathrm{ml}^{-1}$. suspension of $A$. solani 25 days after transplanting (Table 2.1). 'Brandywine' plants were misted with water every 30 minutes for 12 hours after inoculation with $A$. solani.

Disease Measurements. Disease incidence and severity were measured only on susceptible 'Brandywine' plant 3 in each tray. For trays inoculated with $A$. solani, date of first infection, number and size of lesions on pre-selected leaves, and overall percent defoliation was measured on plant 3. For trays inoculated with $M$. incognita, root knot severity was measured on plant 3 by determining the number of galls on $1 \mathrm{~g}$ of roots and the number of eggs recovered from the root system 8 weeks after inoculation. 


\section{Field Study}

Twenty $53.3 \mathrm{~m}^{2}$ plots $(7.3 \mathrm{~m}$ by $7.3 \mathrm{~m})$ were set up at the WVU Organic Research Farm in Dormont (fine-loamy, superactive, mesic, mixed, hapludalf) soil. Four treatments including: 'Brandywine' in monoculture inoculated with either A. solani or M. incognita; 'Brandywine' intercropped with early blight resistant cultivar 'Juliet' and inoculated with A. solani; and, 'Brandywine' intercropped with root knot disease resistant cultivar 'Celebrity' and inoculated with $M$. incognita, were arranged in a randomized complete block design with five replicates. Disease progression in the monoculture was compared with the resistant intercrop. Seven-week-old tomato seedlings were transplanted May 27 in a design alternating resistant and susceptible plants (Figure 2.2).

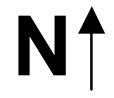

\begin{tabular}{|l|l|l|l|l|l|l|l|}
\hline $\mathbf{S}^{*}$ & $\mathbf{S}^{3}$ & $\mathrm{R}$ & $\mathbf{S}^{3}$ & $\mathrm{R}$ & $\mathbf{S}^{3}$ & $\mathrm{R}$ & $\mathbf{S}^{3}$ \\
\hline $\mathbf{S}^{1}$ & $\mathbf{S}^{2}$ & $\mathrm{R}$ & $\mathbf{S}$ & $\mathrm{R}$ & $\mathbf{S}$ & $\mathrm{R}$ & $\mathbf{S}$ \\
\hline $\mathrm{R}$ & $\mathrm{R}$ & $\mathrm{R}$ & $\mathbf{S}$ & $\mathrm{R}$ & $\mathbf{S}$ & $\mathrm{R}$ & $\mathbf{S}$ \\
\hline $\mathbf{S}^{1}$ & $\mathbf{S}$ & $\mathbf{S}$ & $\mathbf{S}^{2}$ & $\mathrm{R}$ & $\mathbf{S}$ & $\mathrm{R}$ & $\mathbf{S}$ \\
\hline $\mathrm{R}$ & $\mathrm{R}$ & $\mathrm{R}$ & $\mathrm{R}$ & $\mathrm{R}$ & $\mathbf{S}$ & $\mathrm{R}$ & $\mathbf{S}$ \\
\hline $\mathbf{S}^{1}$ & $\mathbf{S}$ & $\mathbf{S}$ & $\mathbf{S}$ & $\mathbf{S}$ & $\mathbf{S}^{2}$ & $\mathrm{R}$ & $\mathbf{S}$ \\
\hline $\mathrm{R}$ & $\mathrm{R}$ & $\mathrm{R}$ & $\mathrm{R}$ & $\mathrm{R}$ & $\mathrm{R}$ & $\mathrm{R}$ & $\mathbf{S}$ \\
\hline $\mathbf{S}^{1}$ & $\mathbf{S}$ & $\mathbf{S}$ & $\mathbf{S}$ & $\mathbf{S}$ & $\mathbf{S}$ & $\mathbf{S}$ & $\mathbf{S}^{2}$ \\
\hline
\end{tabular}

Figure 2.2. Resistant intercrop plot layout. $R=$ resistant cultivar; $S=$ susceptible cultivar; $S^{*}=$ inoculated plant; $S^{1}, S^{2}, S^{3}=$ transect number. $S^{*}$ was inoculated July 13,2001 . Disease and yield data were gathered from designated 'Brandywine' plants in three transects at seven day intervals.

Plants were spaced three feet apart, staked, and mulched with newspaper and straw hay. Plots were alternated according to the pathogen with which they were inoculated, but monoculture or intercropping treatment was randomized within the blocks. Only one 'Brandywine' plant in the Northwest corner of each plot was inoculated. Plants inoculated with $A$. solani were spray inoculated July 
13 with a 20,000 spore $\mathrm{ml}^{-1}$ suspension prepared from 2-week-old cultures of $A$. solani on V-8 juice agar. Cultures were surface-scraped with a sterile blade and, 24 hours later, distilled water was poured on the plates and a paintbrush was used to suspend the conidia. Plots were inoculated in the NW corner with $M$. incognita by planting a heavily infected tomato plant grown for 3-months after inoculation with a single egg mass culture.

Disease Measurements. Early blight disease progression was measured in three separate transects on specified 'Brandywine' plants in each plot every 7 days. Total percent symptomatic leaf area was measured on the pre-selected 'Brandywine' plants. Rate of disease increase ( $r$ ) was calculated by plotting percent symptomatic leaf area over time and determining the slope of the best-fit line with JMP statistical software. Plants were evaluated according to the distance from the inoculated plant in order to identify whether a disease gradient occurred (Table 2.4). Plants at positions of 0 were the inoculated plants, and those at positions of 1 were directly adjacent to the inoculated plants (Figure 2.3)

$\mathbf{N} \quad$\begin{tabular}{|l|l|l|l|l|l|l|l|}
\hline $\mathbf{S}^{\mathbf{0}}$ & $\mathbf{S}^{\mathbf{1}}$ & $\mathrm{R}$ & $\mathbf{S}^{3}$ & $\mathrm{R}$ & $\mathbf{S}^{\mathbf{5}}$ & $\mathrm{R}$ & $\mathbf{S}^{\mathbf{7}}$ \\
\hline $\mathbf{S}^{1}$ & $\mathbf{S}^{1}$ & $\mathrm{R}$ & $\mathbf{S}$ & $\mathrm{R}$ & $\mathbf{S}$ & $\mathrm{R}$ & $\mathbf{S}$ \\
\hline $\mathrm{R}$ & $\mathrm{R}$ & $\mathrm{R}$ & $\mathbf{S}$ & $\mathrm{R}$ & $\mathbf{S}$ & $\mathrm{R}$ & $\mathbf{S}$ \\
\hline $\mathbf{S}^{3}$ & $\mathbf{S}$ & $\mathbf{S}$ & $\mathbf{S}^{3}$ & $\mathrm{R}$ & $\mathbf{S}$ & $\mathrm{R}$ & $\mathbf{S}$ \\
\hline $\mathrm{R}$ & $\mathrm{R}$ & $\mathrm{R}$ & $\mathrm{R}$ & $\mathrm{R}$ & $\mathbf{S}$ & $\mathrm{R}$ & $\mathbf{S}$ \\
\hline $\mathbf{S}^{\mathbf{5}}$ & $\mathbf{S}$ & $\mathbf{S}$ & $\mathbf{S}$ & $\mathbf{S}$ & $\mathbf{S}^{\mathbf{5}}$ & $\mathrm{R}$ & $\mathbf{S}$ \\
\hline $\mathrm{R}$ & $\mathrm{R}$ & $\mathrm{R}$ & $\mathrm{R}$ & $\mathrm{R}$ & $\mathrm{R}$ & $\mathrm{R}$ & $\mathbf{S}$ \\
\hline $\mathbf{S}^{\mathbf{7}}$ & $\mathbf{S}$ & $\mathbf{S}$ & $\mathbf{S}$ & $\mathbf{S}$ & $\mathbf{S}$ & $\mathbf{S}$ & $\mathbf{S}^{7}$ \\
\hline
\end{tabular}

Figure 2.3. Field plot numbering scheme for determination of distance from inoculated plant. Disease gradients were monitored in 'Brandywine' plants numbered according to distance from the inoculated plant $\left(\mathrm{S}^{0}\right)$. 
Rate of lesion expansion was measured on randomly selected old and middle-aged leaves on each of the pre-selected 'Brandywine' plants. Old leaves were randomly chosen from the bottom of the main stem. Middle-aged leaves were randomly chosen from any leaf that was atleast half way up the main stem. The leaves were tagged and a diagram of the leaf was made with lesion location. Monitored lesions were marked with a permanent marker so that the same lesion could be found each week. Yield on 'Brandywine' plants in the same 13 preselected positions was harvested in a single picking and was combined within each plot. Average lesion expansion, area under the disease progress curve (AUDPC), rate of disease spread, and yield in the 'Brandywine' monoculture was compared with 'Brandywine' intercropped with the resistant cultivars.

Root knot severity was measured according to number of galls observed on 5 grams of plant roots harvested randomly on selected 'Brandywine' plants throughout the study.

Statistical Analyses. For the greenhouse study, the block effect was not statistically significant, therefore data were analyzed using a completely randomized two-way analysis of variance (ANOVA) using intercrop treatment and monitor date. Because the two-way interaction effect was significant, a one-way ANOVA and Tukey's honest significant difference (HSD) were used to compare each treatment by date combination.

For the field experiment, AUDPC was calculated by adding percent defoliation due to early blight for each monitoring date over the season. Rate of early blight increase ( $r$-value) was determined by plotting percent symptomatic leaf area over time and calculating the slope of the best-fit line. A logistic model was compared with a linear regression, and the linear regression gave better fits and randomly distributed residuals. Rate of lesion expansion was calculated by plotting lesion diameters over time and calculating the slope of the best-fit line.

Data for the AUDPC, r-values, and rate of lesion expansion were analyzed on a per-plant basis using two-way analysis of variance. Transects within plots did not differ and were treated as replicates. One-way ANOVA and Tukey's HSD 
were used to compare treatment-by-distance combinations for AUDPC, lesion expansion rates, and r-values.

\section{Results}

\section{Greenhouse Study}

Early Blight. Early blight lesions first appeared one week after inoculation on plant 1 and four weeks after inoculation on plant 3. Average symptomatic leaf area due to early blight was greater on the 'Brandywine' monoculture (48\%) than on the intercropped Brandywine (26\%) 11 weeks after inoculation $(P<0.001$, Figure 2.4).

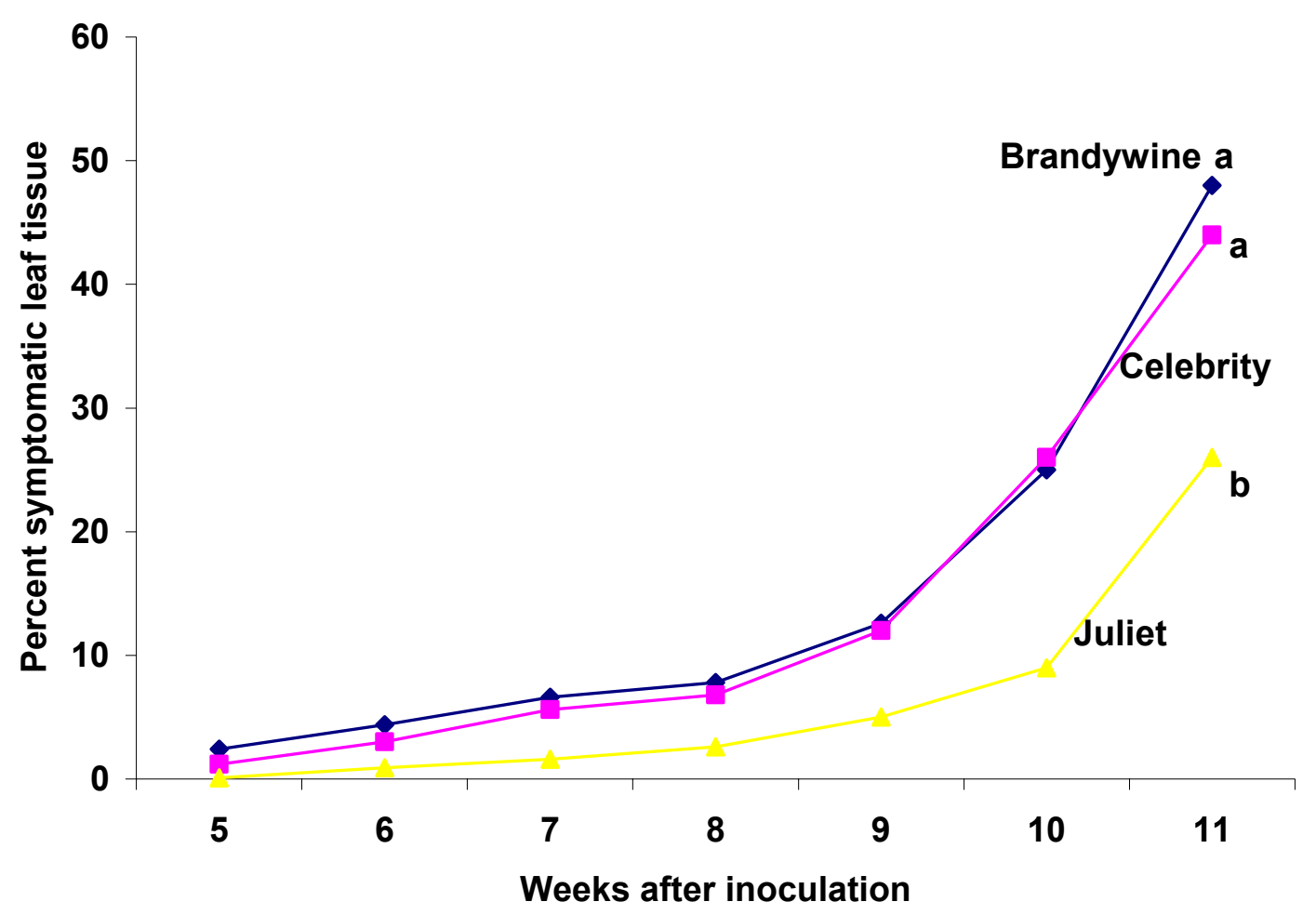

Figure 2.4. Percent leaf tissue of 'Brandywine' (plant 3) with early blight symptoms when planted next to one of three cultivars. Three tomato plants were in each container. The first plant,

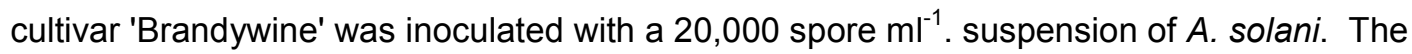
second plant was either cultivar 'Brandywine', 'Celebrity', or 'Juliet'. Disease was measured on 'Brandywine' (plant 3). Early blight percent symptomatic leaf tissue depends on the cultivar planted next to it throughout the experiment. Points followed by the same letter do not differ significantly $(P<0.05)$ according to Tukey's HSD. 
Mean percent symptomatic leaf area due to early blight on plant three over the entire experiment was $14.09 \%$ in monoculture and $6.46 \%$ when intercropped with 'Juliet' $(P<0.001)$. Mean percent symptomatic leaf area was $15.26 \%$ on 'Brandywine' intercropped with 'Celebrity' and was not significantly different from the monoculture, indicating that a cultivar resistant to early blight is required for intercropping to be effective in reducing the spread of disease.

The largest lesion diameter on leaf 3 averaged $4.08 \mathrm{~mm}$ in the monoculture compared to $2.97 \mathrm{~mm}$ in the resistant intercrop (Figure 2.5). The largest lesion diameter on leaf 9 was an average of $2.60 \mathrm{~mm}$ in the monoculture compared to $1.51 \mathrm{~mm}$ in the resistant intercrop (Figure 2.6). Lesion diameter was significantly greater on 'Brandywine' in monoculture for the first half of the experiment, but not toward the end.

Throughout the experiment, the average number of lesions was greater on leaf 3 (14.97) on 'Brandywine' in monoculture than on resistant intercropped 'Brandywine' (7.17, $P<0.001)$. This trend continued for leaf 9 which had an average number of lesions of 6.91 in the monoculture compared to 3.65 on the resistant intercropped 'Brandywine' plants (Table 2.1). Five weeks after inoculation, leaf 3 and 9 on the 'Brandywine' intercropped with 'Juliet' had an average of 0.2 and 0 lesions, respectively, compared to the monoculture which had 2.8 and 1.9 lesions, respectively (Figure 2.7 and 2.8).

Average lesion diameter and average number of lesions on leaf 3 and leaf 9 on 'Brandywine' intercropped with 'Celebrity' were not significantly different from 'Brandywine' in monoculture, but were significantly greater than those from 'Brandywine' intercropped with 'Juliet' $(P<0.001$, Table 2.2). 


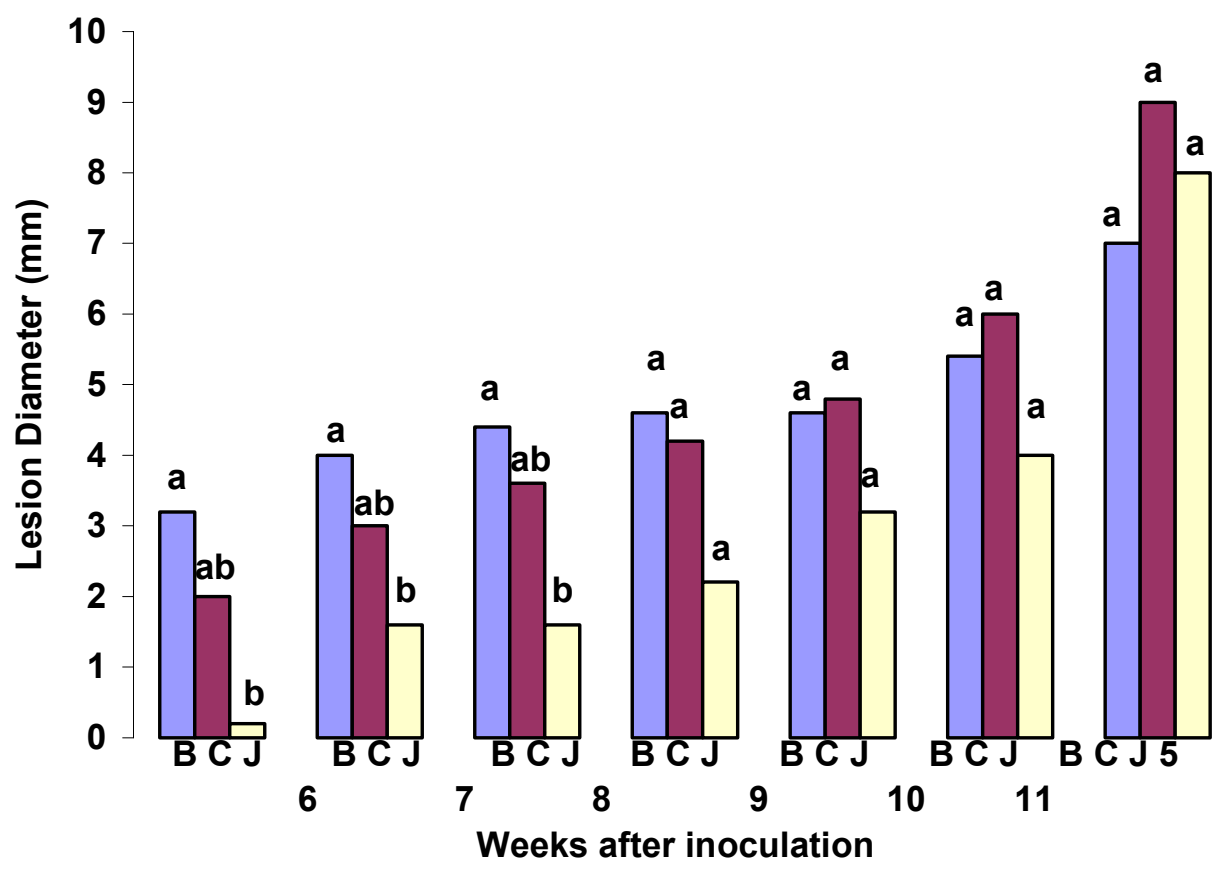

Figure 2.5. Diameter of the largest lesion on leaf 3 of 'Brandywine' (plant 3) when planted next to one of three cultivars. Three tomato plants were in each container. The first plant, cultivar 'Brandywine' was inoculated with a 20,000 spore $\mathrm{ml}^{-1}$. suspension of $A$. solani. The second plant was either cultivar 'Brandywine' (B), 'Celebrity' (C), or 'Juliet' (J). Disease was measured on 'Brandywine' (plant 3). Lesion diameter is independent of the cultivar planted next to it beginning eight weeks after inoculation, but not before. Means in the same week followed by the same letter do not differ significantly $(P<0.05)$ according to Tukey's HSD. 


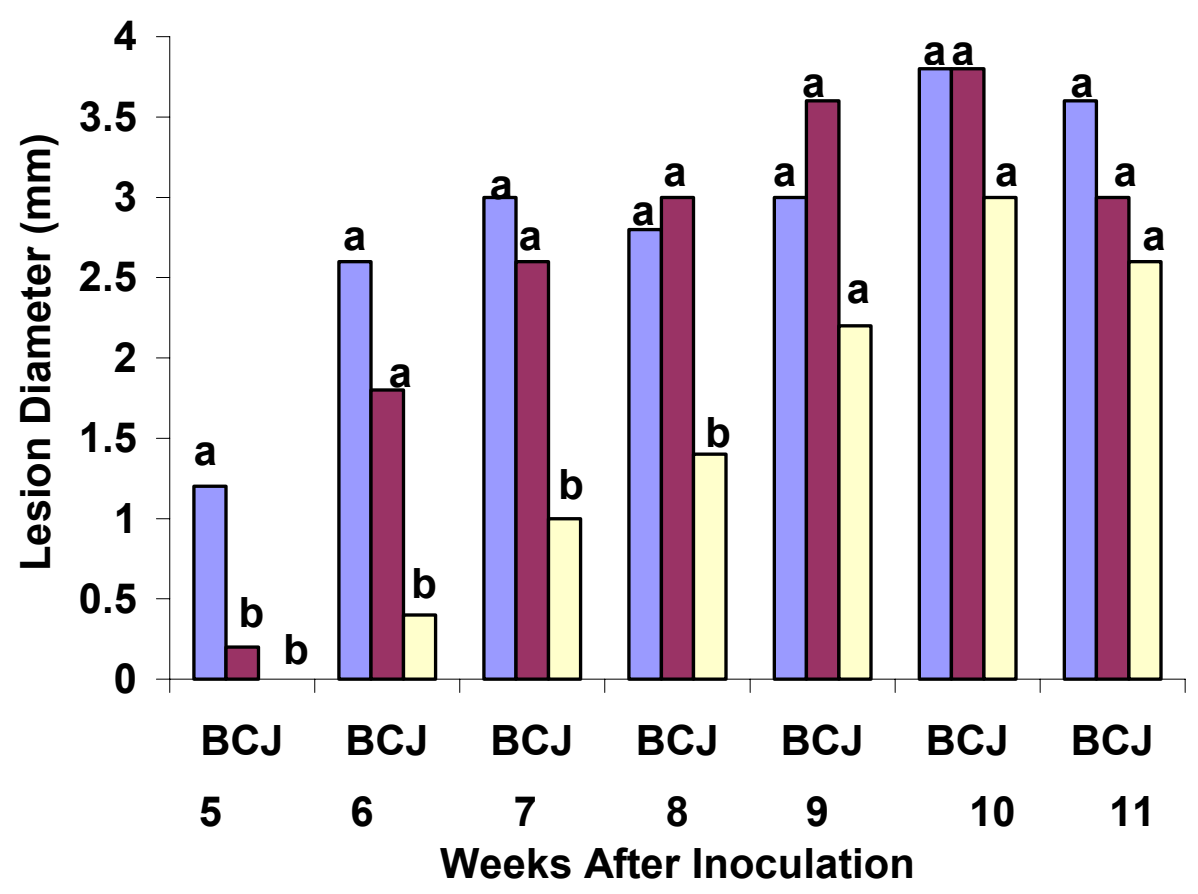

Figure 2.6. Diameter of the largest lesion on leaf 9 of 'Brandywine' (plant 3) when planted next to one of three cultivars. Three tomato plants were in each container. The first plant, cultivar 'Brandywine' was inoculated with a 20,000 spore $\mathrm{ml}^{-1}$. suspension of $A$. solani. The second plant was either cultivar 'Brandywine' (B), 'Celebrity' (C), or 'Juliet' (J). Disease was measured on 'Brandywine' (plant 3). Lesion diameter depends on the cultivar planted next to it the first 8 weeks of the experiment, but not after. Means in the same week followed by the same letter do not differ significantly $(P<0.05)$ according to Tukey's HSD. 


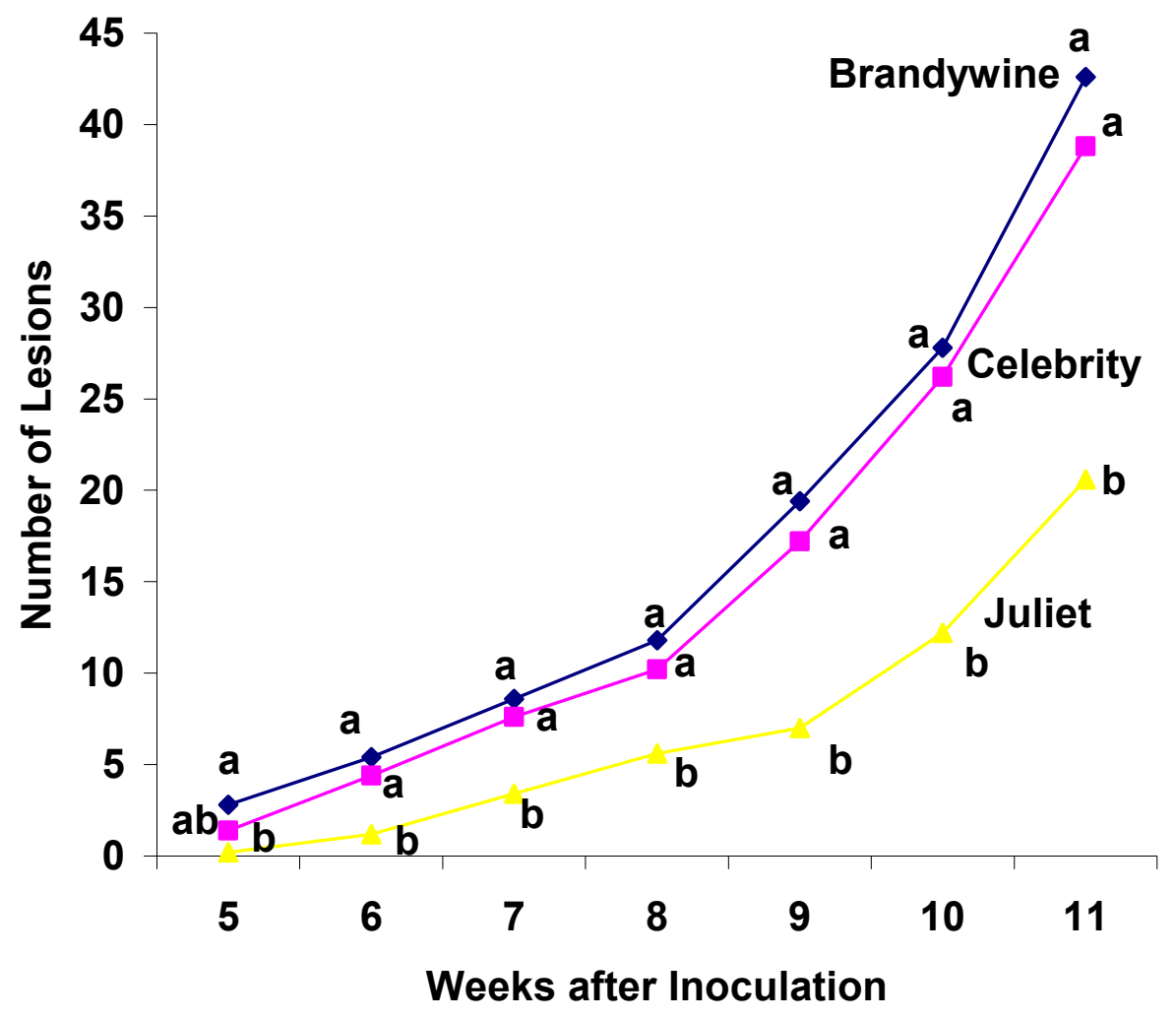

Figure 2.7. Number of early blight lesions on leaf 3 of 'Brandywine' (plant 3) when planted next to one of three cultivars. Three tomato plants were in each container. The first plant, cultivar 'Brandywine' was inoculated with a 20,000 spore $\mathrm{ml}^{-1}$. suspension of $A$. solani. The second plant was either cultivar 'Brandywine', 'Celebrity', or 'Juliet'. Disease was measured on 'Brandywine' (plant 3). Incidence depends on the cultivar planted next to it. Means in the same week followed by the same letter do not differ significantly $(P<0.05)$ according to Tukey's HSD. 


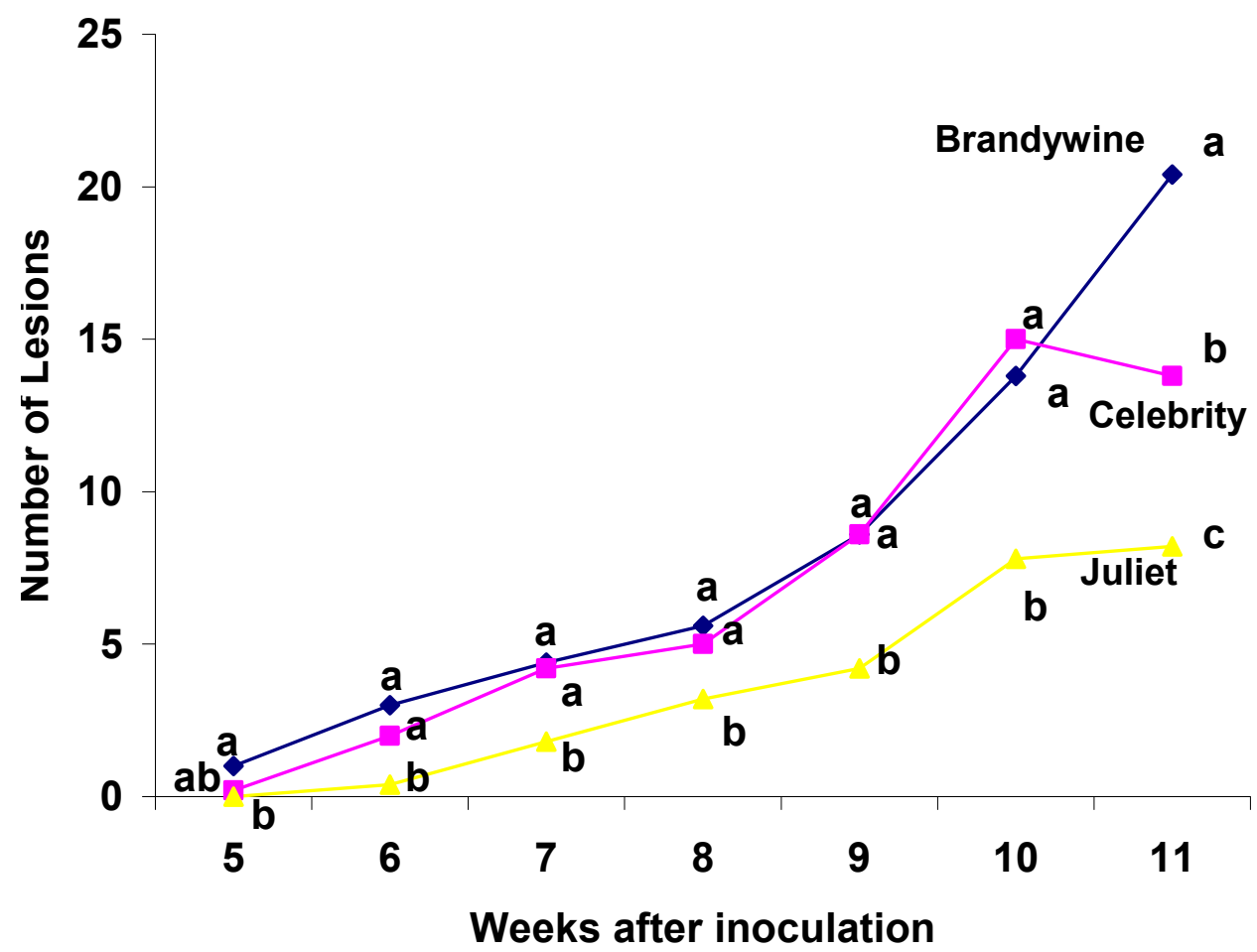

Figure 2.8. Number of early blight lesions on leaf 9 of 'Brandywine' (plant 3) when planted next to one of three cultivars. Three tomato plants were in each container. The first plant, cultivar 'Brandywine' was inoculated with a 20,000 spore $\mathrm{ml}^{-1}$. suspension of $A$. solani. The second plant was either cultivar 'Brandywine', 'Celebrity', or 'Juliet'. Disease was measured on 'Brandywine' (plant 3). Incidence depends on the cultivar planted next to it. Means in the same week followed by the same letter do not differ significantly $(P<0.05)$ according to Tukey's HSD. 
TABLE 2.2. Mean lesion number (\#) and size of largest lesion $(\mathrm{mm})$ on select leaves of 'Brandywine' (plant 3) planted next to one of three cultivars.

Number of lesions Diameter of largest lesion ( $\mathrm{mm})$

\begin{tabular}{lccccc} 
& & & & \% Symptomatic \\
Cultivar of Plant 2 & Leaf 3 & Leaf 9 & Leaf 3 & Leaf 9 & Tissue \\
\hline Brandywine & $16.91 \mathrm{a}$ & $8.11 \mathrm{a}$ & $4.74 \mathrm{a}$ & $2.86 \mathrm{a}$ & $15.26 \mathrm{a}$ \\
Juliet & $7.17 \mathrm{~b}$ & $3.66 \mathrm{~b}$ & $2.97 \mathrm{~b}$ & $1.51 \mathrm{~b}$ & $6.45 \mathrm{~b}$ \\
Celebrity & $15.11 \mathrm{a}$ & $6.97 \mathrm{a}$ & $4.65 \mathrm{a}$ & $2.57 \mathrm{a}$ & $14.09 \mathrm{a}$ \\
\hline
\end{tabular}

Three tomato plants were in each container. The first plant, cultivar 'Brandywine' was inoculated with a 20,000 spore $\mathrm{ml}^{-1}$. suspension of $A$. solani. The second plant was either cultivar 'Brandywine', 'Celebrity', or 'Juliet'. Disease was measured on 'Brandywine' (plant 3). Means followed by the same letter in the same column do not differ significantly $(P<0.05)$ according to Tukey's HSD.

Root Knot Disease. The number of $M$. incognita eggs recovered from the roots $\left(P_{f}\right)$ on 'Brandywine' plant 3 in each container was used to determine the effect of intercropping with resistant cultivar 'Celebrity' on the spread of root knot nematode (Figure 2.9). The log of $\mathrm{P}_{\mathrm{f}}$ on plant three was significantly lower when intercropped with 'Celebrity' than in monoculture and when intercropped with 'Juliet' $(P<0.05)$. 


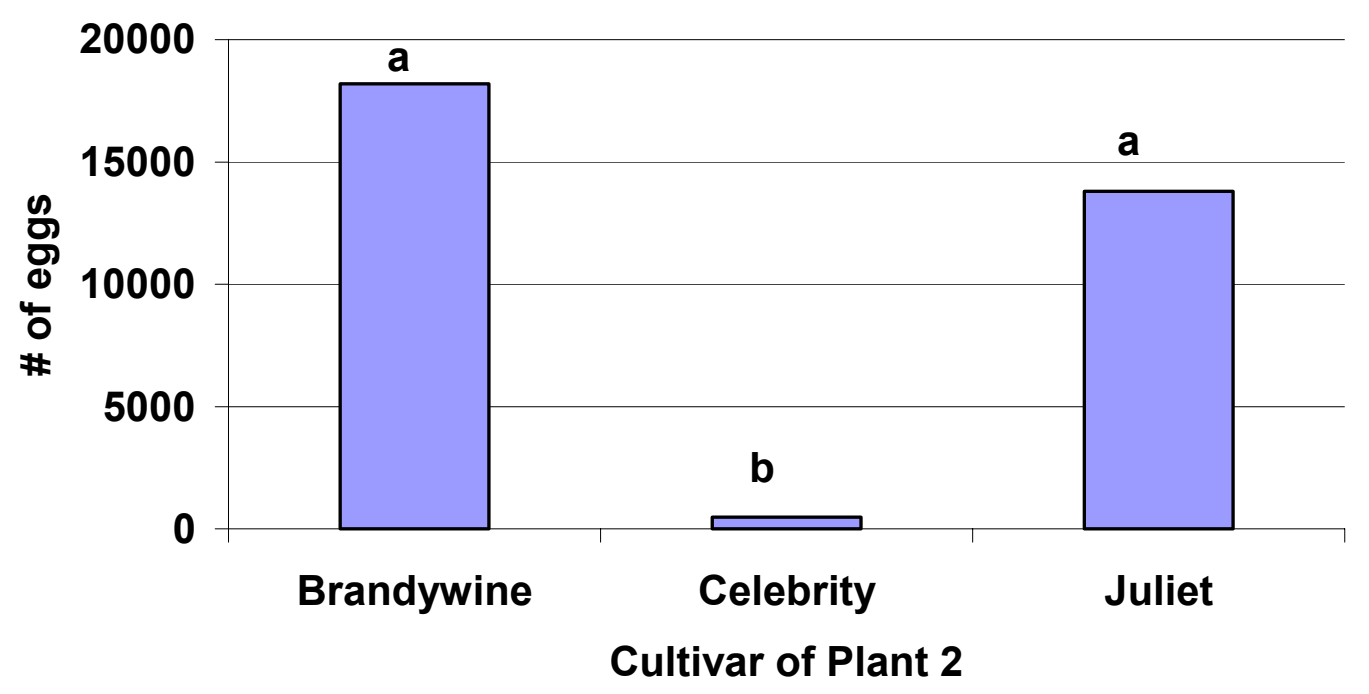

Figure 2.9. Mean number of $M$. incognita eggs recovered on 'Brandywine' (plant 3 ) planted next to the same cultivar, a root knot resistant cultivar ('Celebrity'), or another susceptible cultivar ('Juliet'). Three tomato plants were in each container. The first plant, cultivar 'Brandywine' was inoculated with 3,000 M. incognita eggs. The second plant was either cultivar 'Brandywine', 'Celebrity', or 'Juliet'. Disease was measured on 'Brandywine' (plant 3). Means followed by the same letter do not differ significantly $(P<0.05)$ according to Tukey's HSD.

Nematode galling and egg production on 'Brandywine' in monoculture did not differ from that on 'Brandywine' intercropped with a different susceptible cultivar ('Juliet') but was significantly $(P<0.001)$ reduced on 'Brandywine' intercropped with the root knot disease resistant cultivar 'Celebrity' (Figure 2.10). 


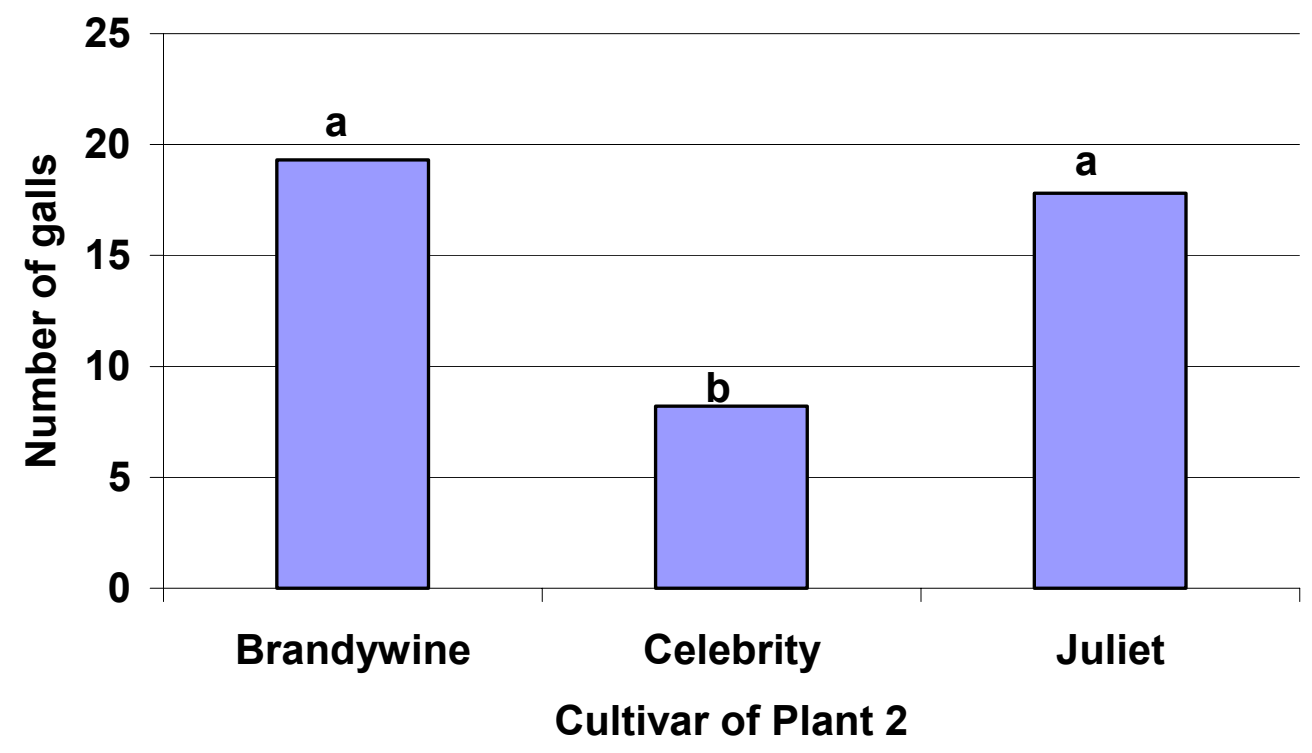

Figure 2.10. Mean number of galls per gram of root on 'Brandywine' (plant 3 ) planted next to the same cultivar, a root knot resistant cultivar ('Celebrity'), or another susceptible cultivar ('Juliet'). Three tomato plants were in each container. The first plant, cultivar 'Brandywine' was inoculated with 3,000 M. incognita eggs. The second plant was either cultivar 'Brandywine', 'Celebrity', or 'Juliet'. Disease was measured on 'Brandywine' (plant 3). Means followed by the same letter do not differ significantly $(P<0.05)$ according to Tukey's HSD.

\section{Field Study}

M. incognita did not spread beyond the inoculated plants and so those plots are not considered in the analysis. Weather throughout the summer was ideal for the spread of early blight. A few naturally occuring lesions were spotted in early July about the time that corner plants were inoculated. Heavy symptoms occurred on inoculated plants 1 week after inoculation and disease increased linearly throughout the summer until frost on October 7 . An outbreak of late blight began in late August and percent symptomatic leaf area due to late blight was rated separately from early blight between $8 / 24$ and $9 / 14$. By late September it became difficult to differentiate between defoliation due to the two diseases. Therefore, the last three weeks of observation (9/21 to 10/5) were removed from the analysis. 
An early blight disease gradient was established across the plots from the point of inoculation. Early blight AUDPC $(P=0.038)$ and r-values $(P=0.006)$ were significantly lower in the intercrop compared with the monoculture when averaged across all the measured plants.

Rates of disease increase (r-values) on 'Brandywine' were determined at different distances from the inoculated plant for both treatments (Table 2.4). The tomato plants that were measured for disease in each plot included some that were directly adjacent to the inoculated plant (position 1) and others that had resistant cultivar 'Juliet' between them and the inoculated plant (positions 3, 5 and 7). Rate of disease increase and lesion expansion rates on plants at position 1 can be compared with those at positions 3,5 , and 7 to assess whether induced resistance played a part in disease reduction in 'Brandywine' plants. Rate of disease increase was statistically the same on the inoculated plant and 'Brandywine' at position 1 in both the monoculture and the intercrop. However, rate of disease increase on 'Brandywine' was progressively lower on intercropped plants at positions 3,5 , and 7 . 
TABLE 2.3. Rate of early blight disease progress ( $r$ ) and Area Under the Disease Progress Curve (AUDPC) on 'Brandywine' in monoculture or intercropped with resistant cultivar 'Juliet' at different positions from the inoculated plant (Figure 2.3).

\begin{tabular}{lccc}
\hline \hline & Position & r-value & AUDPC \\
\hline Intercrop & 0 & $1.23 \mathrm{a}$ & $744 \mathrm{~A}$ \\
& 1 & $1.23 \mathrm{a}$ & $384 \mathrm{~B}$ \\
& 3 & $0.74 \mathrm{c}$ & $318 \mathrm{BC}$ \\
& 5 & $0.71 \mathrm{c}$ & $313 \mathrm{BC}$ \\
Monoculture & 7 & $0.61 \mathrm{~d}$ & $226 \mathrm{C}$ \\
& 0 & $1.24 \mathrm{a}$ & $695 \mathrm{~A}$ \\
& 1 & $1.21 \mathrm{a}$ & $450 \mathrm{~B}$ \\
& 3 & $1.15 \mathrm{ab}$ & $383 \mathrm{~B}$ \\
& 5 & $1.05 \mathrm{~b}$ & $373 \mathrm{~B}$ \\
& 7 & $0.99 \mathrm{~b}$ & $308 \mathrm{BC}$ \\
\hline
\end{tabular}

Distance $=$ Number of plants from the inoculated plant $($ Plant Distance $=0)$. Plants were spaced $90 \mathrm{~cm}$ apart both between and within rows. $P$-values were based on linear regression of disease severity versus time. Means were of fifteen replicates. Means followed by the same letter do not differ significantly $(P<0.05)$ according to Tukey's HSD.

The average lesion expansion rate was significantly greater on older than younger leaves $(P=0.034)$. The rates on both old and middle aged leaves were lower on intercropped 'Brandywine' than in the monoculture, but the differences were not significant (Table 2.4). 'Brandywine' yield was $17.3 \%$ greater when intercropped with 'Juliet' than with monoculture $(P=0.001$, Table 2.4). 
TABLE 2.4. Rate of early blight lesion expansion and yield on 'Brandywine' plants in monoculture or intercropped with early blight-resistant cultivar 'Juliet'.

\begin{tabular}{lccc}
\hline \hline & \multicolumn{3}{c}{ Lesion expansion rate $\left(\mathrm{mm}\right.$ day $\left.^{-1}\right)$} \\
\cline { 2 - 3 } Treatment & Old & Middle & Yield $\left(\mathrm{kg} \mathrm{plot}^{-1}\right)$ \\
\cline { 2 - 4 } Intercrop & $0.57 \mathrm{a}$ & $0.35 \mathrm{a}$ & $48.3 \mathrm{a}$ \\
Monoculture & $0.65 \mathrm{a}$ & $0.53 \mathrm{a}$ & $58.4 \mathrm{~b}$ \\
\hline$P$ - value & $P=0.16$ & $P=0.094$ & $P<0.001$ \\
\hline
\end{tabular}

Yield on 'Brandywine' plants in the same 13 pre-selected positions was harvested in a single picking and was combined within each plot. Means followed by the same letter do not differ significantly $(P<0.05)$ according to Tukey's HSD.

Lesion expansion at different distances from the inoculated plant did not change depending on the treatment, however there was a trend toward a reduced lesion expansion rate on resistant intercropped 'Brandywine' (Table 2.5) compared to monoculture.

TABLE 2.5. Rate of early blight lesion expansion on tomato cultivar 'Brandywine' in a monoculture or a resistant intercrop at different positions from the inoculated plant.

\begin{tabular}{ccc}
\hline \hline Treatment & Position & Lesion Expansion Rate $\left(\mathrm{mm} \mathrm{day}^{-1}\right)$ \\
\hline Intercrop & 1 & $0.45 \mathrm{a}$ \\
Monoculture & 1 & $0.66 \mathrm{a}$ \\
Intercrop & 3 & $0.47 \mathrm{a}$ \\
Monoculture & 3 & $0.51 \mathrm{a}$ \\
\hline
\end{tabular}

Means of 15 replicates followed by the same letter do not differ significantly $(P=0.13)$ according to Tukey's HSD. 


\section{Discussion}

Early blight AUDPC was reduced on a susceptible tomato cultivar intercropped with a resistant cultivar compared to susceptible monoculture in both greenhouse and field experiments, despite the prediction that resistant mixtures have a limited effect on disease reduction with larger plants (Van der Plank, 1968). These data support the findings of Garrett and Mundt (2000) who found that Phytophthora infestans was reduced on susceptible potato cultivars in resistant mixtures.

One of the reasons for contradictory effects of resistant intercrops on reducing disease is that the level of inoculum differs at each site. Extremely high levels of inoculum entering the field may overcome the effects of the resistant plants (Wolfe and Barrett, 1980). Garrett and Mundt (2000) found that the effect of resistant intercropping was greater in plots with a general placement of initial inoculum as opposed to a focal inoculum source. This contrasts with the findings of Mundt and Leonard (1986) that crown rust reduction on oats is greater from a focal inoculum source. Results from the current study are confounded by the fact that naturally occurring lesions were already present throughout the plot when the focal epidemic started. However, a disease gradient was established in both the monoculture and intercropped plots, and disease reduction on plant 3 was observed in the greenhouse study. This suggests that the majority of initial inoculum was from the experimentally inoculated plant in the NW corner and that resistant intercropping is effective in reducing early blight from a focal inoculum source.

Resistant intercrops are predicted to be more effective for smaller host plants, such as wheat and barley, because inoculum is less likely to land on the source individual. However, resistant mixtures may be more effective at reducing disease from pathogens that can be wind-dispersed, such as $A$. solani and $P$. infestans, because auto-infection is more limited than with pathogens with splash-dispersed spores (Garrett and Mundt, 2000). Therefore, despite the large size of the tomato plants, the effectiveness of the mixture indicates that inoculum 
was dispersed far from individual plants. In addition, the effect of large plant size may have been lessened because the cultivars were both indeterminate and plants were intertwined in the plots by late July.

Crop mixtures are predicted to be more effective with pathogens that have a shallow dispersal gradient from the inoculum source. The number of lesions was lower on 'Brandywine' planted with 'Juliet' in the greenhouse study indicating spore blockage by the resistant cultivar. The lower incidence of early blight indicates that disease arrived at 'Brandywine' later when planted with 'Juliet' and signifies a shallow dispersal gradient for $A$. solani. Reduced inoculum would not account for the $11 \%$ reduction in largest lesion diameter, unless all the spores were blocked by 'Juliet' and disease arrived later. An alternative explanation is that a resistance response might be initiated in 'Brandywine' by the production of MeSA in neighboring 'Juliet' tomato plants (Shulaev et al., 1997; Chapter 3). Though replicate tomato plants were in the same greenhouse, it is unlikely that enough MeSA would be produced to induce resistance in leaves that were not close to the source. Monitoring SA levels in paired plants would determine if the smaller lesion diameter in 'Brandywine' paired with 'Juliet' is due to induced resistance (Chapter 3).

Rate of individual lesion expansion was monitored in the field experiment, as opposed to diameter of the largest lesion, to elucidate the mechanism of disease reduction (Berger et al., 1997). Lesions on middle and old aged leaves expanded faster on 'Brandywine' in monoculture, but this was not statistically significant ( $P=0.0936$ and 0.1602 , respectively). In addition, the rate of lesion expansion is not significantly different between plant 1 and 3 or between the monoculture and the intercrop, though there is a trend toward reduced lesion expansion in the resistant intercrop (Table 2.6). Plants with a distance of 1 were adjacent to both the inoculated plant and 'Juliet' and were therefore good indicators of the mechanism of disease reduction. Because the rate of disease increase was the same on plants with a distance of 1 in the monoculture and the intercrop, volatile MeSA from 'Juliet' would not explain the trend toward a reduction in lesion size on plant 3. More experiments are needed to clarify the 
role of various mechanisms of disease reduction on susceptible plants in resistant intercrops. For example, salicylic acid levels in plants in monoculture and resistant mixtures should be compared in the field.

Crop mixtures with many resistant varieties can have greater disease reduction due to induced resistance because its effect increases with the quantity of avirulent spores (Calonnec et al., 1996). In this study, mixed plots were composed of a susceptible and a resistant cultivar, ruling out disease reduction from induced resistance due to increased numbers of avirulent spores. Therefore, it is likely that the main mechanism of disease reduction was the decreased proportion of susceptible plant material and because early blight lesions on resistant cultivar 'Juliet' do not produce spores (Chapter 1). However, the trend toward reduced lesion expansion in resistant intercropped plots suggests that induced resistance could be a contributing mechanism and warrants further investigation.

Containers inoculated with $A$. solani, but intercropped with 'Celebrity' (resistant to $M$. incognita) were used to discern whether early blight disease reduction was due to the presence of a resistant cultivar or simply to increased crop diversity. Defoliation on 'Brandywine' was not significantly different when planted with 'Celebrity' compared to 'Brandywine' monoculture. Therefore disease reduction due to diversity is more effective when resistant cultivars are present. In addition, 'Brandywine' inoculated with M. incognita, but intercropped with 'Juliet' had similar root knot disease severity as 'Brandywine' in monoculture (Figure 2.7 and 2.8).

'Brandywine' plants adjacent to inoculated plants had the similar r-values across both treatments, however r-values are significantly lower in the intercropped plots at positions of 3,5 and 7. Similar reduction in rate of disease increase was observed with Colletotrichum sublineolum (causes sorghum anthracnose) and Exserohilum turcicum (causes leaf blight) on susceptible sorghum intercropped with maize or a resistant sorghum cultivar (Ngugi et al., 2001). The resistant mixture was more effective at reducing the rate of increase of $E$. turcicum than C. sublineolum due to differences in mode of dispersal. Like 
A. solani, E. turcicum is wind-dispersed and has a shallow disease gradient compared to splash-dispersed spores, such as $C$. sublineolum. The decrease in rate of disease increase in these cases was attributed to the buffer created by the resistant cultivar between the inoculum source and the susceptible plant. The reduction in disease increase on plants with a position of 5 and 7 in the monoculture can likewise be attributed to limited auto-infection.

In conclusion, the reduction in lesion diameter and the trend toward reduced lesion expansion support the hypothesis that intercropped 'Brandywine' may have reduced disease because of induced resistance in addition to a reduction in susceptible plant material. Experiments which monitor salicylic acid levels in the field might help to further understand the role of induced resistance in mixtures. Effectiveness of resistant intercropping for a delay in early blight progression on susceptible cultivars has not been tested under natural inoculation. Resistant mixtures may require the use of other cultural practices for effective control of early blight. However, the $17 \%$ increase in crop yield on 'Brandywine' intercropped with 'Juliet' indicates that resistant intercropping for disease protection on susceptible cultivars, where practical, is a viable alternative for disease control. 


\section{CHAPTER 3}

\section{Salicylic acid production as an indicator of the induction of resistance to Alternaria solani in intercropped tomato.}

\section{Introduction}

Infection of plants with a necrotizing pathogen can enhance resistance to subsequent infections by various fungal, bacterial and viral pathogens. This induced resistance, known as systemic acquired resistance (SAR), extends to plant tissue distant from the infection site and can persist for weeks after the initial infection. Salicylic acid (SA) plays an important role in signal transduction in plants and is believed to initiate SAR (Malamy et al., 1990).

$\mathrm{SA}$ is also associated with pathogen-specific resistance such as the hypersensitive response (HR). The HR involves the localized necrosis of host tissue immediately surrounding the infection site and is initiated by the interaction of a host resistance gene product with a specific pathogen-produced elicitor (Enyedi and Raskin, 1993). SA has been shown to increase in the leaf zone surrounding pathogen infection as early as 14 hours after inoculation (Malamay et al., 1990). This increase clearly precedes tissue injury and necrosis and suggests that SA plays a role in the HR.

Many studies have set out to identify cellular elements that directly interact with SA in order to understand the mechanism by which plants couple SA perception, SAR gene induction, and the manifestation of resistance. For example, SA has been shown to function as a catalase-binding molecule, which results in increased active oxygen species that are involved in the HR (Conrath et al., 1995). SA has also been found to activate the expression of genes that encode pathogenesis-related proteins (Yalpani et al., 1991). Although the mechanisms by which plants induce resistance remain largely unknown, some of the steps in the various signal transduction pathways are beginning to be uncovered (Vernooij et al., 1994). The involvement of SA in both SAR and localized resistance (HR) suggests that a common molecular pathway dependent upon SA accumulation may function in each of these resistance mechanisms. 
Salicylic acid has been shown to accumulate in tomato leaf tissue inoculated with pathogens that induce a resistance response (Spletzer and Enyedi, 1999). Increases in the levels of SA in leaf tissue correlated with reduced lesion size and number. The application of SA to tomato roots also induces PRprotein expression and SAR (Spletzer and Enyedi, 1999). Control of tomato diseases is usually achieved by routine applications of chemical fungicides and copper sprays due to the absence of tomato cultivars that have adequate levels of resistance. As an alternative to fungicide application, exogenous application of SA to roots of hydroponically grown tomato can increase resistance against $A$. solani, the causal agent of early blight (Spletzer and Enyedi, 1999).

The lack of known resistance genes in tomato against $A$. solani has led to exploration of alternative methods of control. Whether SA produced in a resistant cultivar could help to protect susceptible cultivars should be explored. One hypothesis for a way that SA could pass from one plant to another is by a neighboring plant sensing the volatile methyl-salicylic acid and activating a defense response (Shulaev et al., 1997). Another possibility is that SA could pass through arbuscular mycorrhizal fungi joining root systems via hyphal bridges (see Appendix 1).

The objective of this study was to determine if SA from an early blight resistant tomato cultivar will induce SA production in a susceptible cultivar growing in the same pot. Volatile MeSA has been shown to induce resistance in neighboring plants (Shulaev et al., 1997), but it is also possible that SA may pass to neighboring plants through root grafts or mycorrhizal fungi (Appendix 1). Inducing plant resistance has been suggested as an alternative to fungicide application in control of plant diseases such as early blight when there are no resistant cultivars available (Spletzer and Enyedi, 1999). Resistance may be induced in the field by spraying SA or other related chemical inducers, inoculating with plant growth promoting rhizobacteria (van Loon et al., 1998; Yan and Reddy, 1999), or by crop mixtures (Lannou et al., 1995). The ability of 'Juliet' to induce resistance and reduce the severity of early blight on 'Brandywine' was tested in the greenhouse by measuring the expression of SA in 
both cultivars planted alone, and planted in the same pot. The expression of SA after inoculation with $A$. solani was measured over two weeks in these two cultivars to determine differences between resistant and susceptible cultivars in rate of induction of SA expression.

Secondly, the production of SA 72 hours after inoculation with $A$. solani was determined in sixteen different tomato cultivars to evaluate whether SA production is a good indicator of resistance to early blight. Greenhouse screening for resistance to early blight has been unreliable. For example, cultivars with moderate resistance show no difference in symptoms compared with susceptible cultivars. Success depends on seedling age, plant resistance level, inoculum quality and quantity, inoculation technique, and environmental conditions in the greenhouse. In this study, varieties screened for resistance to early blight in the field were used to assess whether if SA production in the greenhouse is correlated with field resistance. SA production after inoculation with a pathogen of interest might be used to indicate varietal disease resistance in the greenhouse.

\section{Materials and Methods}

SA expression in 'Brandywine' and 'Juliet'. Thirty five 2-week-old transplants of each cultivar were planted in $15-\mathrm{cm}$-diameter pots containing a potting soil starter mix. Four weeks later, 28 plants of each cultivar were spray inoculated with 20,000 A. solani spores $\mathrm{ml}^{-1}$ until run-off on all of the leaves. Seven plants of each cultivar were sprayed with distilled water as a non-inoculated control. Plants were left in a mist bed for 24 hours after inoculation. Four inoculated plants and one non-inoculated control plant of each cultivar were harvested at 0 , $24,48,72,96,120$ and 336 hours after inoculation. One gram of leaf tissue sampled randomly from different leaves was frozen at $-80^{\circ} \mathrm{C}$ and analyzed for SA content.

Paired planting Experiment. Two 2-week old tomato transplants were planted in 15-cm-diameter pots in a potting soil starter mix separated by a plastic barrier (Figure 3.1). Plant 1 consisted of either 'Brandywine' or an early blight resistant 
cultivar ('Juliet', '99199', '99197', or '99203'). Plant 2 always was a 'Brandywine' transplant. There were five replicates for each of the five treatments.

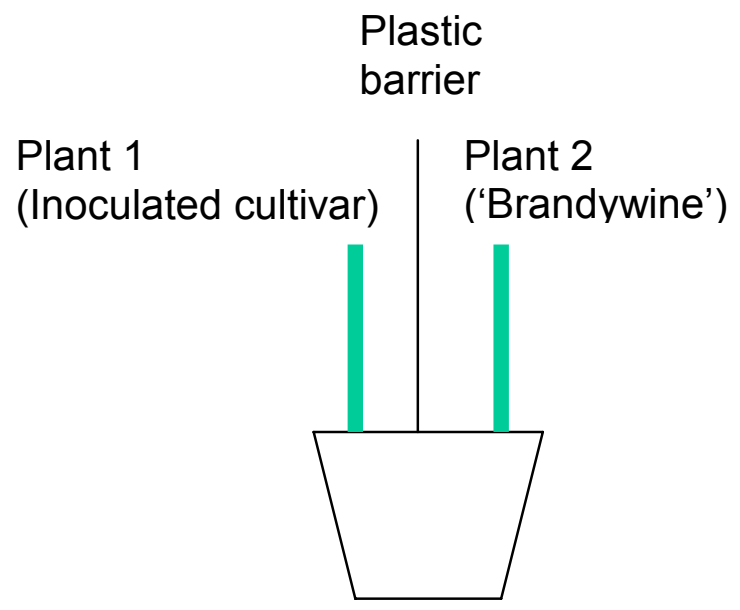

Figure 3.1. Planting design for the paired-plant experiment. Two tomato plants were planted in the same plot. Plant 1 was inoculated with 20,000 A. solani spores $\mathrm{ml}^{-1}$ and 96 hours later, plant 2 was inoculated. One gram of leaf tissue was harvested from both plants 72 hours after inoculation.

Plant 1 was spray inoculated with 20,000 A. solani spores $\mathrm{ml}^{-1}$ until run-off 4 weeks after transplanting. A plastic sheet between the two plants ensured that only Plant 1 was inoculated initially. Ninety six hours later, Plant 2 ('Brandywine') was spray inoculated in the same way. Containers were left on the mist bed for 24 hours after each inoculation to allow for spore penetration. Leaves from all inoculated plants were harvested for SA extraction 72 hours after inoculation. SA content on 'Brandywine' planted in the same container with the resistant cultivars was compared with those planted with another 'Brandywine'.

Cultivar Screening Assays. Six replicates of the 16 tomato cultivars were seeded and 2-week-old seedlings were transplanted to 4" pots in potting soil. One month later, four plants of each cultivar were spray inoculated with an $A$. solani spore suspension of 20,000 spores $\mathrm{ml}^{-1}$ and placed on a mist bed for 24 hours. The remaining two plants of each cultivar were sprayed with distilled water as a control. One gram of leaf tissue was harvested for SA extraction 72 hours after inoculation (or mock-inoculation). The sixteen tomato cultivars were 
analyzed for SA content 0 and 72 hours after inoculation with $A$. solani to limit the influence of volatile MeSA on the SA accumulation in the leaves (Shulaev, et al., 1997). Basal SA levels, production 72 hours post-inoculation, and the difference between the two were correlated with level of disease resistance expression in the field.

HPLC Analysis. Salicylic acid levels were measured in leaf tissue by high performance liquid chromatography. HPLC is a separation technique involving mass transfer between a stationary phase and a liquid mobile phase. The components of a mixture are forced to flow through a chromatographic column under high pressure. The column contains a stationary phase, which is a dense bed of small porous particles that interact with the various components of the mixture. In adsorption chromatography, separation is based on the different affinities of the components of the mixture for the stationary phase. In reversephase chromatography, a type of adsorption chromatography, the stationary bed is non-polar (hydrophobic), while the mobile phase is polar. Using this technique, increasingly non-polar compounds take longer to pass through the column. SA is a polar compound that can be detected in this way using reverse-phase adsorption HPLC. Once SA passes through the column, a spectrofluorescence detector is needed for its identification. SA absorbs ultraviolet light at a wavelength of $310 \mathrm{~nm}$ and re-emits it at $395 \mathrm{~nm}$. Using this information, along with a known elution time, the presence and amount of SA in the sample can be determined.

SA Extraction. One gram of leaf tissue was ground in $2.5 \mathrm{ml}$ of $90 \%$ methanol with a mortar and pestle. Extract from all samples were centrifuged at 12,000 $\mathrm{g} g$ for 15 minutes. The supernatants were dried under a speed vacuum sample concentrator and re-suspended in $0.4 \mathrm{ml}$ of $5 \%$ (wt/vol) trichloroacetic acid. This material was re-centrifuged at $12,000 \mathrm{xg}$ for $10 \mathrm{~min}$. The supernatant was partitioned with $0.8 \mathrm{ml}$ of $1: 1$ mixture of ethyl acetate/cyclopentane containing $1 \%$ isopropanol. The resulting upper phase was dried under a speed vacuum 
sample concentrator and re-suspended in $100 \mu$ of the HPLC mobile phase. SA was separated isocratically with $14 \%$ methanol in $20 \mathrm{mM}$ sodium acetate buffer (pH 5.0) at a flow rate of $1 \mathrm{ml} \mathrm{min}^{-1}$ (Yalpani et al.,1991). HPLC separation of SA was determined by fluorescence detectors after separation on a C18 reversephase HPLC column ( $25 \mathrm{~cm} \times 4.6 \mathrm{~mm} \times 5 \mu \mathrm{m}$ packing). SA was excited with ultraviolet light at $310 \mathrm{~nm}$, and detected by emission at $395 \mathrm{~nm}$. Five SA standards at different concentrations were injected at the beginning of every HPLC run and a curve was generated to calculate the quantity of SA injected in each sample. SA standards also were injected throughout the run to account for variation in elution time and peak areas. Each run lasted for 30 minutes and injection of the mobile phase alone resulted in no peaks ensuring that SA was not bound to the column and contaminating samples.

\section{Results}

\section{SA extraction.}

The retention time for the SA standard was approximately 10 minutes (Figure 3.2). Using this extraction procedure, other minor unidentified peaks were evident at 3,5 , and 7 minutes, but there were no peaks with a retention time similar to salicylic acid. The SA standard curve was linear and all samples fell within concentrations on the curve (Figure 3.3). Three parts shoot sample mixed with 1 part $100 \mathrm{ng} \mathrm{SA}$ in mobile phase produced only one peak at 9.3 minutes, indicating that the signal was SA.

\section{SA expression in 'Brandywine' and 'Juliet'.}

SA levels on 'Brandywine' and 'Juliet' differed significantly throughout the experiment. 'Brandywine' had higher basal SA levels than 'Juliet'. However, 24 hours after inoculation, 'Juliet' SA levels surpassed 'Brandywine' and were higher for the remaining 2 weeks. The peak level of SA expression was 120 hours after inoculation for both cultivars. At 120 hours, SA reached 11 times the basal level in 'Juliet', compared with only four times the basal level in 'Brandywine' (Figure 3.4). 


\section{Paired-Plant Experiment.}

SA levels on plant 1 at 72 hours after inoculation depended on the cultivar, with 'Juliet' having the largest values (529 $\mathrm{ng} \mathrm{g}^{-1}$, Table 3.1). 'Brandywine' paired with 'Juliet' averaged $184 \mathrm{ng} \mathrm{g}^{-1}$ more SA than when it was paired with another 'Brandywine', however this trend was only marginally significant statistically $(P=$ 0.089).

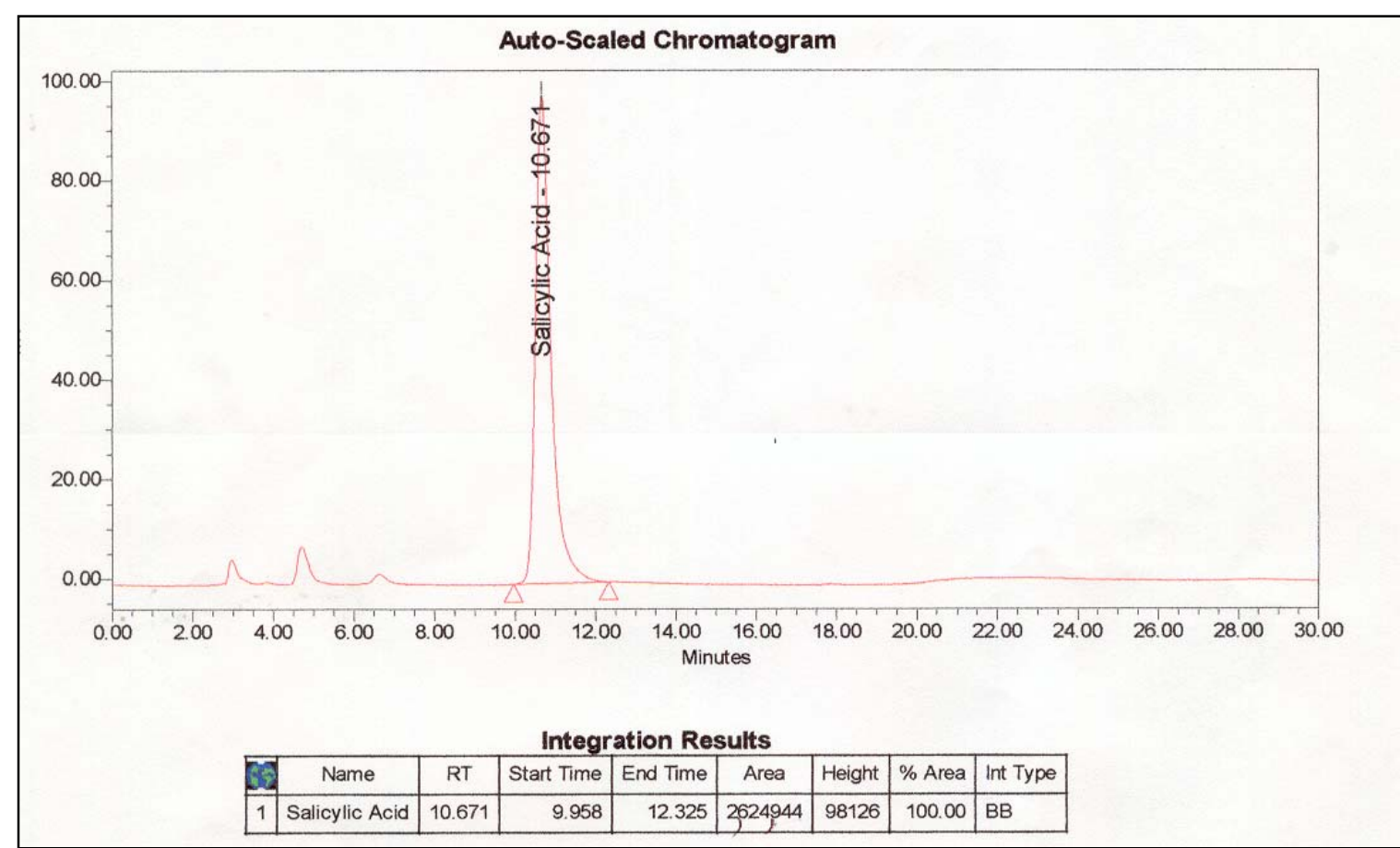

Figure 3.2. Example HPLC chromatogram. Salicylic acid (SA) was extracted from one gram of non-inoculated 'Brandywine' leaf material $\left(S A\right.$ content $\left.=103.44 \mathrm{ng} \mathrm{g}^{-1}\right)$. 


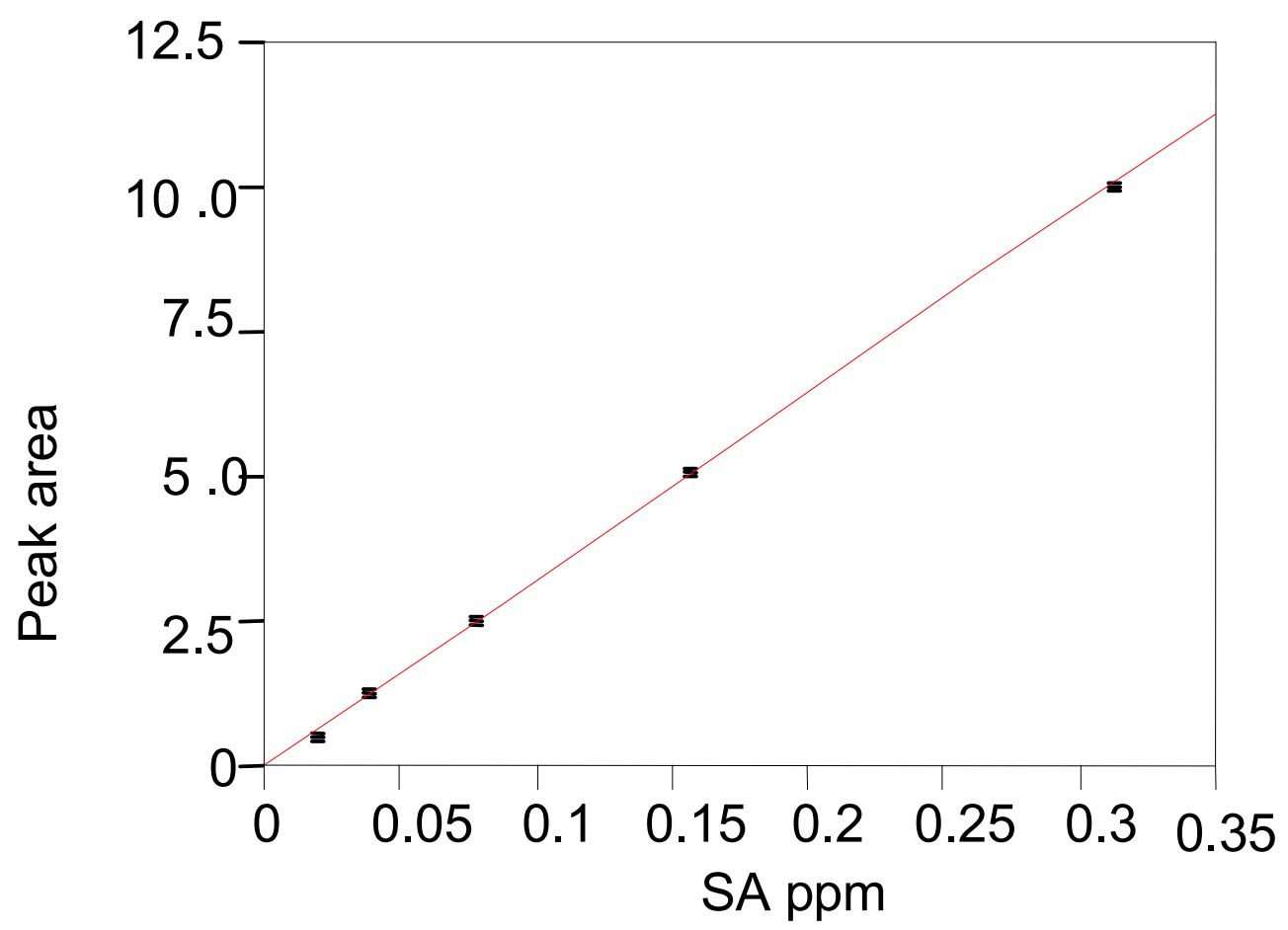

Figure 3.3. Salicylic acid (SA) standard curve. The equation from the best fit line was used to calculate the quantity injected in each sample based on the peak area. Peak area $\left(x 10^{6}\right)=3373$ +32327000 ppm. A new curve was generated for each run. 


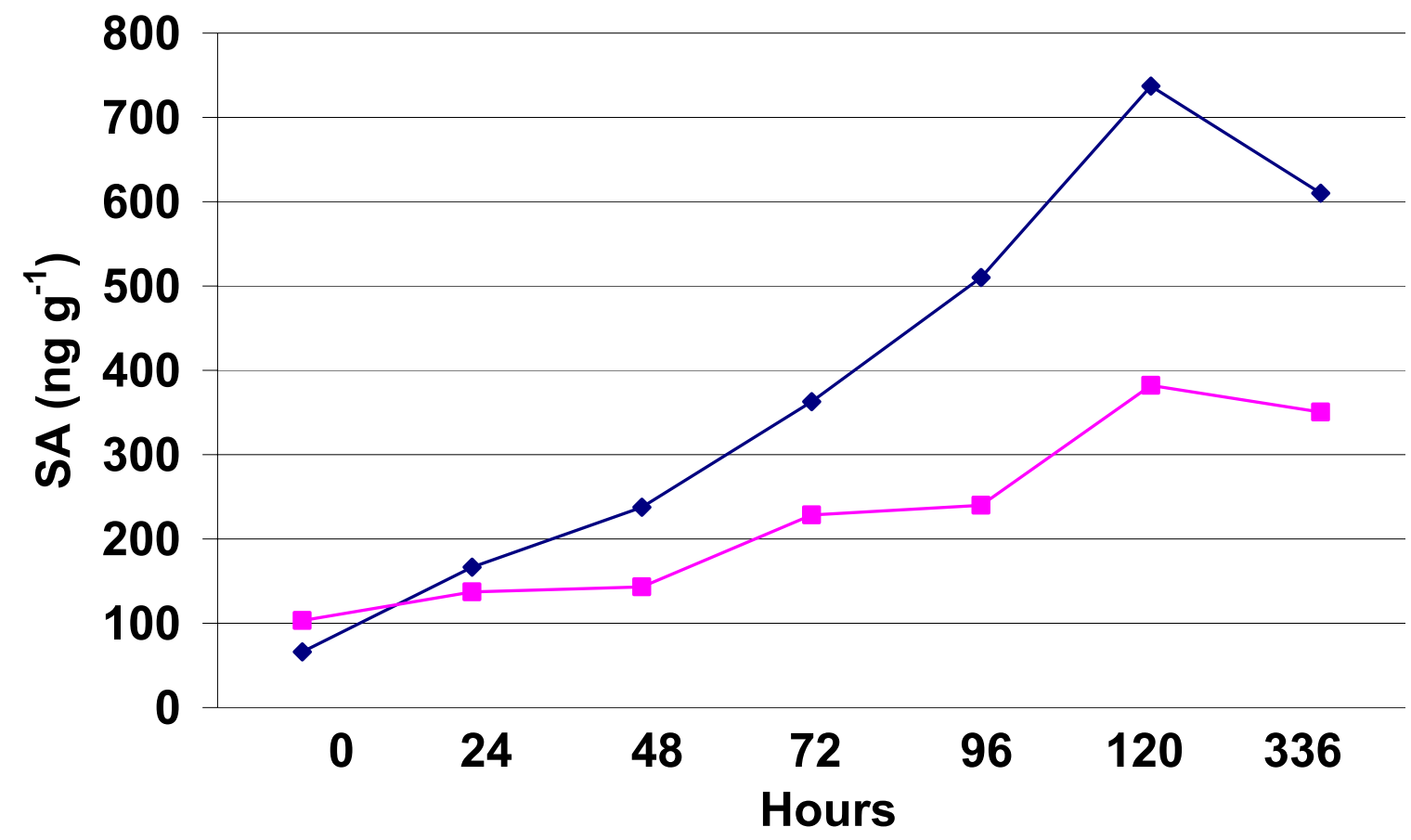

Figure 3.4. Increase in salicylic acid (SA) in early blight resistant cultivar 'Juliet' and heirloom cultivar 'Brandywine' after inoculation with $A$. solani. All points differed significantly throughout the experiment $(P<0.05)$ according to Tukey's HSD. 
Table 3.1. Salicylic acid (SA) levels ( $\mathrm{ng} \mathrm{g}^{-1}$ gram leaf) 72 hours after inoculation with solani in a paired-plant experiment.

\begin{tabular}{lcc} 
& \multicolumn{2}{c}{ SA ng g $^{-1}$ leaf } \\
\cline { 2 - 3 } Cultivar of Plant 1 & Plant 1 & Plant 2 (Brandywine) \\
\hline Brandywine & $130 \mathrm{a}$ & $198 \mathrm{a}$ \\
99199 & $342 \mathrm{~b}$ & $247 \mathrm{a}$ \\
99197 & $471 \mathrm{~b}$ & $265 \mathrm{a}$ \\
99203 & $486 \mathrm{~b}$ & $215 \mathrm{a}$ \\
Juliet & $529 \mathrm{c}$ & $382 \mathrm{a}$ \\
\hline$P$ - values & $P=0.001$ & $P=0.089$ \\
\hline
\end{tabular}

Plant 1 was inoculated 96 before neighboring Plant 2 (Figure 3.1). Means are of five replicates.

Means followed by the same letter in the same column do not differ significantly $(P<0.05)$ according to Tukey's HSD.

\section{Cultivar Trial.}

At 72 hours after inoculation, 'Red Currant' produced the highest level of $\mathrm{SA}$, and had the fourth largest increase in SA production. 'Juliet' had the lowest basal SA concentration at $85 \mathrm{ng} \mathrm{g}^{-1}$, but produced the second largest increase in SA after infection (Table 3.2). '99199' had the third largest basal concentration of SA and the largest increase after 72 hours. 
Table 3.2. Area Under the Disease Progress Curve (AUDPC) of 16 cultivars in a field trial and salicylic acid (SA) levels 72 hours after inoculation with Alternaria solani in the greenhouse.

\begin{tabular}{ccccc}
\hline & & \multicolumn{3}{c}{ SA $\left(\mathrm{ng} \mathrm{g}^{-1}\right)$} \\
\cline { 5 - 6 } Cultivar & AUDPC & 72 hours* & Non-inoculated & Increase \\
\hline Daybreak & $224 \mathrm{a}$ & $456 \mathrm{ab}$ & $165 \mathrm{a}$ & 291 \\
Brandywine & $214 \mathrm{ab}$ & $382 \mathrm{ab}$ & $120 \mathrm{a}$ & 262 \\
Green Zebra & $198 \mathrm{abc}$ & $340 \mathrm{ab}$ & $175 \mathrm{a}$ & 165 \\
Johnney's 361 & $194 \mathrm{abc}$ & $259 \mathrm{a}$ & $181 \mathrm{a}$ & 78 \\
Valley Girl & $191 \mathrm{abc}$ & $286 \mathrm{a}$ & $192 \mathrm{a}$ & 94 \\
Striped German & $191 \mathrm{abc}$ & $481 \mathrm{~b}$ & $232 \mathrm{a}$ & 249 \\
Arkansas Traveler & $190 \mathrm{abc}$ & $288 \mathrm{a}$ & $166 \mathrm{a}$ & 122 \\
Celebrity & $188 \mathrm{abc}$ & $354 \mathrm{ab}$ & $240 \mathrm{a}$ & 114 \\
Sungold & $183 \mathrm{bc}$ & $326 \mathrm{~b}$ & $214 \mathrm{a}$ & 112 \\
Prudence Purple & $162 \mathrm{c}$ & $382 \mathrm{~b}$ & $168 \mathrm{a}$ & 214 \\
Matt's Wild Cherry & $123 \mathrm{~d}$ & $748 \mathrm{c}$ & $435 \mathrm{~b}$ & 313 \\
99199 & $121 \mathrm{~d}$ & $992 \mathrm{~d}$ & $351 \mathrm{~b}$ & 641 \\
Red Currant & $119 \mathrm{~d}$ & $1116 \mathrm{~d}$ & $765 \mathrm{c}$ & 351 \\
99197 & $114 \mathrm{~d}$ & $418 \mathrm{~b}$ & $250 \mathrm{a}$ & 168 \\
99203 & $111 \mathrm{~d}$ & $574 \mathrm{bc}$ & $210 \mathrm{a}$ & 364 \\
Juliet & $105 \mathrm{~d}$ & $393 \mathrm{ab}$ & $85 \mathrm{~d}$ & 308 \\
\hline
\end{tabular}

* Mean of four plants

${ }^{* *}$ Mean of two plants

AUDPC in the field is compared with SA concentration ( $\mathrm{ng} \mathrm{g}^{-1}$ fresh weight) in tomato leaves 72 hours after inoculation with $A$. solani or distilled water on various tomato cultivars. Means followed by the same letter in the same column do not differ significantly $(P<0.05)$ according to Tukey's HSD. 
Early blight AUDPC values in the field were weakly correlated with basal SA levels $(P=0.0827$, Figure 3.5$)$, and were significantly correlated with SA levels 72 hours after inoculation $(P=0.0117$, Figure 3.6), and the increase of SA 72 hours after inoculation $(P=0.016$, Figure 3.7). Though there are several outliers, there is a trend toward increased SA production with greater field resistance.

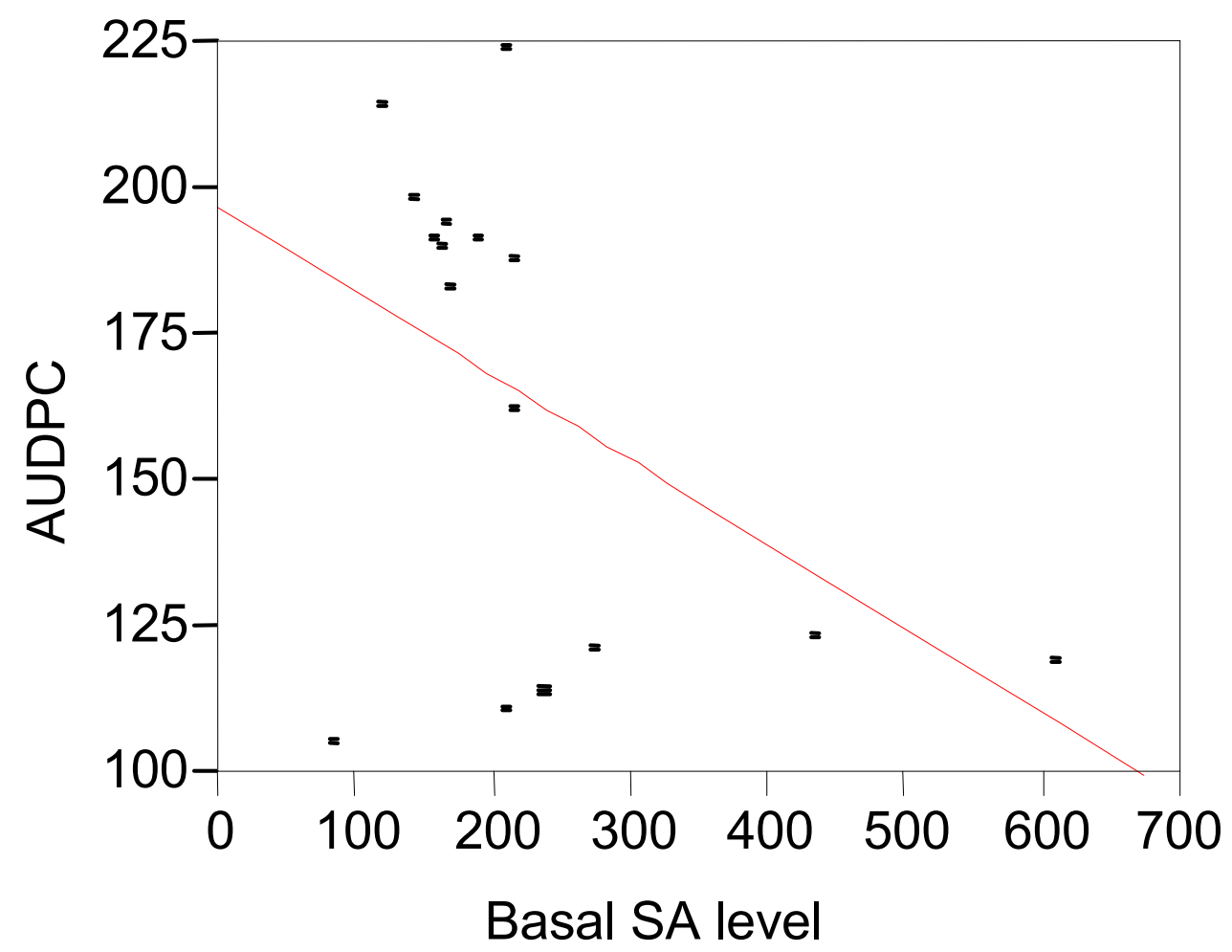

Figure 3.5. Linear regression of early blight AUDPC in the field on salicylic acid (SA) basal levels in 16 tomato cultivars (AUDPC $=197-0.14$ (Basal SA levels), $P>0.083$, $\mathrm{R}^{2}$ adj. = 0.14). 


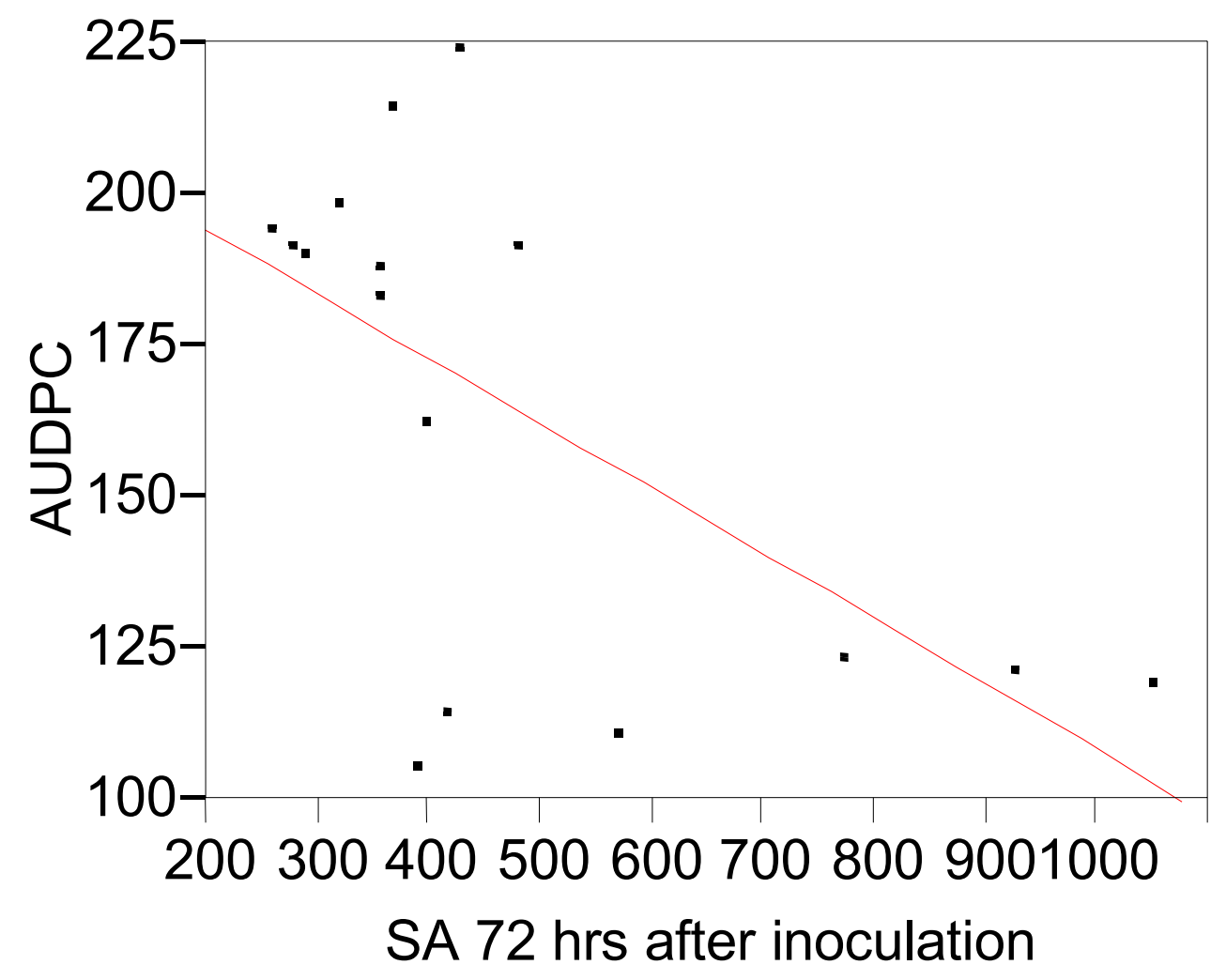

Figure 3.6. Linear regression of early blight AUDPC in the field on salicylic acid (SA) $72 \mathrm{hrs}$ after inoculation with Alternaria solani in 16 tomato cultivars (AUDPC $=216-0.11$ (SA at $72 \mathrm{hrs),} P>$ $0.012, R^{2} \operatorname{adj}=0.33$ ). 


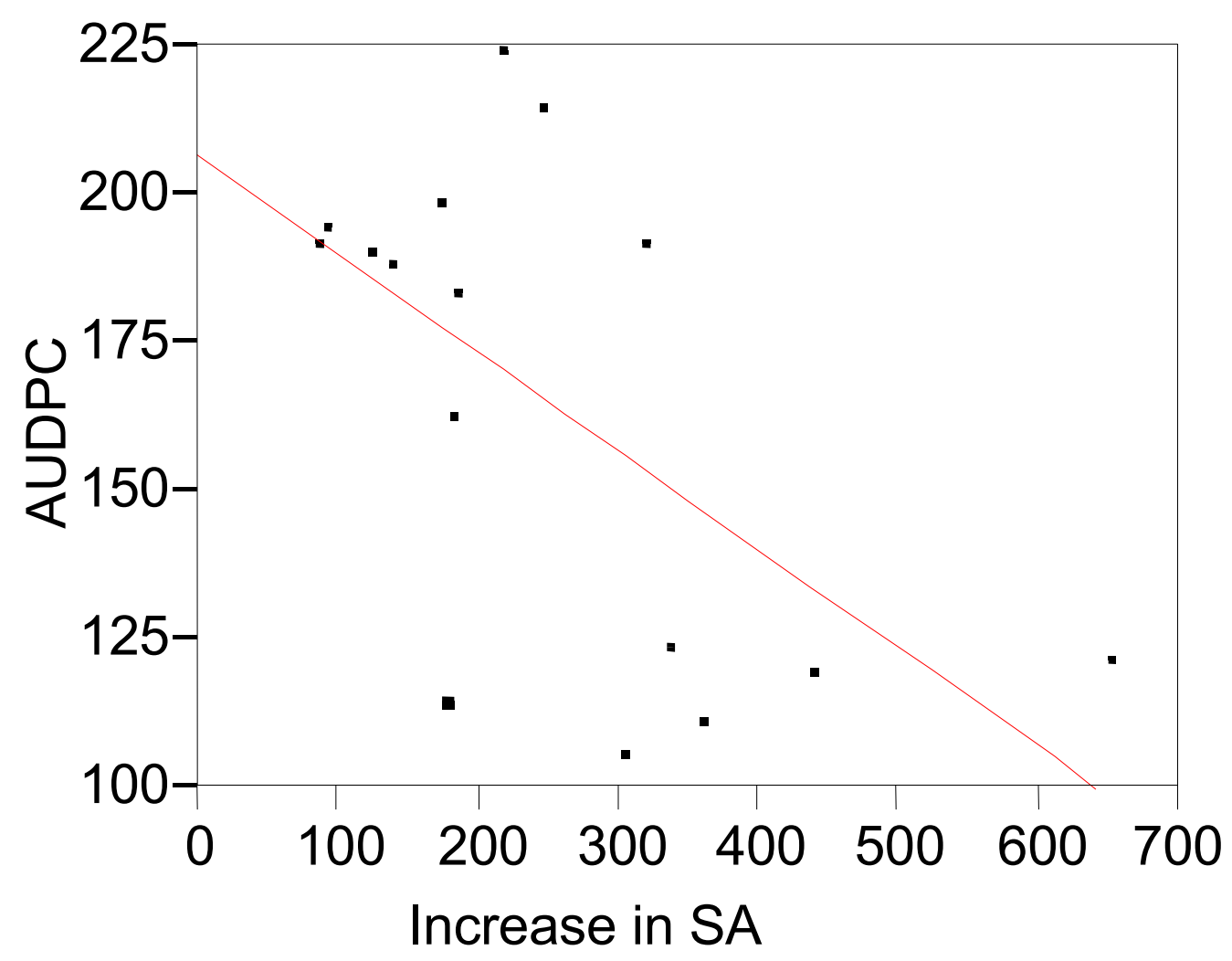

Figure 3.7. Linear regression of early blight AUDPC in the field on the increase in salicylic acid (SA) levels $72 \mathrm{hrs}$ after inoculation with Alternaria solani in 16 tomato cultivars (AUDPC $=206$ 0.17 (increase), $P>0.016, \mathrm{R}^{2}$ adj. $=0.30$ ).

SA production was then compared with early blight resistance in the field using early blight AUDPC. Basal SA levels, on non-inoculated plants, were not as strongly correlated with field resistance as the increase in SA 72 hours after inoculation. 'Juliet', the most resistant cultivar in the field, had the lowest basal SA levels, but one of the highest increases in SA production 72 hours after inoculation. 'Prudence Purple', an heirloom cultivar with no documented resistance to early blight, showed intermediate resistance in the field and one of the highest increases in SA production 72 hours after inoculation. The two cherry cultivars, 'Red Currant' and 'Matt's Wild Cherry', were among the most resistant in the field trial and showed some of the highest increases in SA 
production as well. A cultivar that does not follow this trend is '99197', which had high field resistance, but low SA production 72 hours after inoculation.

\section{Discussion}

SA accumulates in leaf tissue following infection by an avirulent pathogen, but SA levels have not been reported in susceptible cultivars and compared to resistant ones. Though SA accumulation in susceptible cultivars has not been measured, a susceptible cultivar of tomato has the ability to take up exogenous SA and express resistance to $A$. solani (Spletzer and Enyedi, 1999). The link between a SA response and a hypersensitive reaction (Conrath et al., 1995) suggests that resistant cultivars can accumulate SA more quickly than susceptible cultivars. In a test of this hypothesis, early blight resistant cultivar 'Juliet' showed a more rapid accumulation of SA than 'Brandywine'. This supports the hypothesis that faster accumulation of SA upon pathogen recognition occurs in resistant cultivars than in susceptible cultivars.

Tobacco plants that are unable to produce SA (nahG mutants) have larger lesions than wild type plants, indicating that $S A$ is directly involved in inhibiting lesion expansion. A. solani does not produce spores until lesions are greater than $3 \mathrm{~mm}$ (Jones and Jones, 1991), therefore, plants that can accumulate SA more quickly have the ability to block further spread of the pathogen. A. solani has the ability to penetrate 'Juliet' leaves, but lesion expansion does not increase beyond $3 \mathrm{~mm}$ (Chapter 1 and 2). The rapid accumulation of SA in 'Juliet' leaves may be responsible for the inability of $A$. solani to produce spores on this cultivar.

Despite reports that volatile MeSA induces resistance in neighboring plants, this phenomena has yet to be demonstrated outside a growth chamber (Shulev et al., 1997). In addition, several studies have shown a reduction in disease on susceptible cultivars when interplanted with resistant cultivars in the field, but the mechanism of disease reduction was not elucidated (Zhu et al., 2000; Kousik and Ritchie, 1996; Ngugi et al., 2001; Garrett and Mundt, 2000). To better understand the role of salicylic acid in reducing disease in resistant intercrops, SA was measured in susceptible plants paired with resistant plants 
expressing SAR. Though 'Brandywine' SA levels almost doubled when paired with resistant cultivars, this trend was not statistically significant. The increase in SA observed in 'Brandywine' when paired with resistant cultivars may or may not be sufficient to translate to a decrease in AUDPC observed in intercropped 'Brandywine' in the field. These results suggest, however, that it might be fruitful to monitor SA levels in 'Brandywine' intercropped with resistant cultivars in the field. In addition, SA conjugates such as SA 2-O- $\beta$-D-glucoside (SAG), which accumulate over time and provide a slow-release form of SA, should be monitored as well. A better understanding of how levels of SA and its conjugates vary in the field throughout the year would contribute to our understanding of its role in disease resistance.

Peak SA production in both 'Brandywine' and 'Juliet' occurred 120 hours after inoculation, which is consistent with peak levels on tobacco after inoculation with TMV (Malamy et al., 1990). However, increases were 11 times basal levels in 'Juliet' compared to only 4 times basal levels in 'Brandywine', suggesting that the amount is just as important as the rate of SA increase. SA production 72 hours after inoculation varied greatly among the 16 tomato cultivars, but the level required for induction of SAR remains to be reported. It is likely that the increase in SA and levels at 72 hours after inoculation are more important than basal levels for determining resistance to a pathogen. However, some outliers in these SA correlations, such as '99197', suggest that there are other mechanisms for resistance in these cultivars. Monitoring SA accumulation after inoculation over time might be a better indicator of resistance than monitoring at one time period. Repetition of experiments on field resistance and SA accumulation after inoculation is needed to confirm results presented here. 


\section{APPENDIX}

\section{Detection of Salicylic Acid in the Hyphae of Vesicular Arbuscular Mycorrhizae Infecting Tomato After Inoculation with Pseudomonas syringae pv. phaseolicola.}

Arbuscular mycorrhizal fungi (AMF) are endomycorrhizal fungi that grow intracellularly, forming swellings (vesicles) and branches (arbuscules) inside the penetrated cells. AMF are zygomycetes in the order Glomales and are important for sustainable agricultural production (Alexopoulos et al., 1996). They are found associated with the roots of most agricultural and horticultural plants as well as grasses, weeds, cacti, tropical plants and some hardwood trees. Mycorrhizal associations form better in soils with low nutrient levels. The fungus provides the plant with increased water and nutrient absorption, tolerance to drought, high temperature and heavy metals, as well as protection from certain plant pathogenic nematodes and fungi. In exchange, the fungus receives carbohydrates and nutrients from the plant, on which it is completely dependent.

The objective of this study is to look for the presence of SA in the hyphae of AMF infecting tomato 72, 96, and 120 hours following inoculation with Pseudomonas syringae pv. phaseolicola. P. syringae is non-pathogenic on tomato and therefore a HR should be initiated. It is hypothesized that SA will accumulate in the roots and shoots of mycorrhizal tomatoes that are inoculated. It is also hypothesized that SA is present in VAM that infect tomato that are expressing SAR. This seems likely because SA is present in the phloem of plants expressing the HR and VAM receive carbohydrates and vitamins from the phloem of the host.

\section{Methods}

Plant and Inoculation Material. Twenty one 3-week-old tomato seedlings were transplanted into $600-\mathrm{ml} \mathrm{D-40} \mathrm{pots} \mathrm{(Stuewe} \mathrm{\&} \mathrm{Sons)} \mathrm{and} \mathrm{filled} \mathrm{with} 20$ parts sand,10 parts sterilized field soil, and 1 part VAM inoculum five weeks prior to inoculation with Pseudomonas syringae pv. phaseolicola. VAM inoculum was 
obtained from WVU's INVAM culture collection and contained Glomus clarum, Glomus intraradices, and Glomus etunicatum hyphae and spores. Each pot contained one tomato cultivar 'Brandywine' and one tomato cultivar 'Juliet'.

Single colonies of $P$. syringae pv. phaseolicola were grown in Luria Burtani liquid medium for 48 hours on a shaker. The culture was diluted 1:10 with sterilized distilled water. Tomatoes were inoculated by forcing the bacteria into the underside of a leaf with a syringe. All leaflets on the third leaf from the base were inoculated with $3 \mathrm{ml}$ inoculum. Fifteen of the 20 plants were inoculated with $P$. syringae pv. phaseolicola and the other five were inoculated with Luria Burtani liquid medium diluted 1:10 with sterilized distilled water as a control. SA $1 \mathrm{mM}$ solution was injected into the underside of the youngest fully expanded leaf 48 hours after inoculation due to failure of a strong hypersensitive reaction in the tomato leaf. Caution was taken to ensure that the SA solution did not enter the soil or touch the neighboring 'Brandywine' plant.

Tissue collection. At 0 (non-injected), 72, 96, and 120 hours after SA injection, hyphal samples were collected from the five replicate plants. Hyphae were collected by gently shaking the dirt free from the rest of the soil. Remaining roots and soil were blended with water at high speed for three seconds. Root fragments and debris were collected in a 35-mesh sieve and hyphae were trapped in a $27-\mu \mathrm{m}$ pore sieve. Same size soil particles mixed with hyphae were washed with water into a petri dish and hyphal fragments were left overnight to aggregate on the surface. All hyphae that were collected on the surface were used for SA extraction.

Salicylic Acid Extraction and Analysis. SA extraction followed the method described in Chapter 3 above, except all hyphae and debris collected on the surface of the petri dish were ground in $0.5 \mathrm{ml} \mathrm{90 \%} \mathrm{methanol.} \mathrm{To} \mathrm{determine}$ $\beta$-glucosyl-salicylic acid, the methanolic leaf extract was dried and re-suspended in $0.5 \mathrm{ml}$ hydrolysis buffer $\left(100 \mathrm{mmol}\right.$ of sodium acetate buffer $\mathrm{L}^{-1}, \mathrm{pH} 5.5$, containing 20 units of $\beta$-glucosidase). After 1.5 hours of incubation at $37^{\circ} \mathrm{C}$, extracts were acidified to $\mathrm{pH} 1.0$ with $10 \%$ trichloroacetic acid and subjected to SA extraction and analyzed with HPLC as above (Spletzer and Enyedi, 1999). 
SA and SAG values were added for one way ANOVA and means comparison using Tukeys HSD $(P=0.05)$.

\section{Results}

Salicylic acid was recovered from the hyphae of mycorrhizae colonizing all plants, including that of tomato plants not injected with SA (0 hours). SA levels were statistically higher in hyphae 96 hours after injection than that of hyphae at 0 (no SA injected) and 72 hours after injection. Two of the samples at 120 hours were lost, therefore there were only three replicates for this treatment. The experiment should be repeated with more replicates and an analysis of SA in the neighboring non-inoculated plant at longer time intervals.

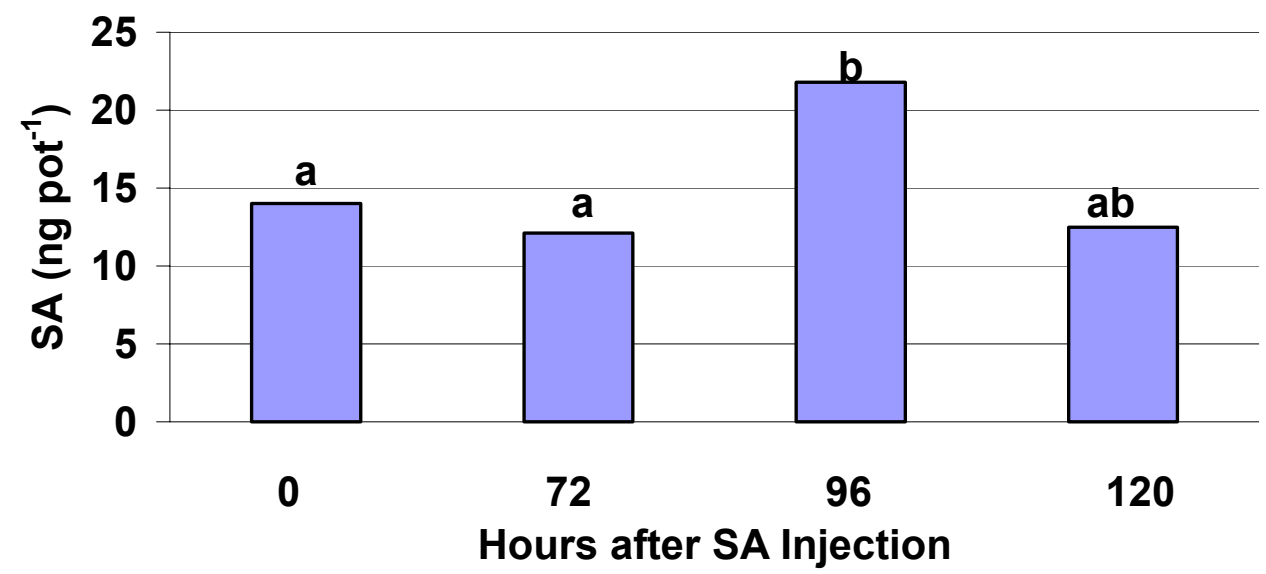

Figure A.1. Hyphal salicylic acid (SA) content. The area under the SA peak of the HPLC chromatogram was used to determine the amount of SA in all the hyphae of VAM colonized tomato 0 (non-injected control), 72, 96 and 120 hours after injection of $3 \mathrm{ml}$ of $1 \mathrm{mM} \mathrm{SA}$ into one compound leaf.

Nanogram amounts of SA have been shown to induce resistance in cucumber plants, implying that the low levels in hyphae reported here may be enough to induce resistance in a neighboring plant (Meyer et al., 1999). The induction of SAR from nanogram amounts of SA in tissue with high levels of basal SA, such as tomato (Chapter 3 ), is only possible if there is a control 
mechanism that prevents the triggering of SAR at basal levels, such as the sequestering of SA. If this is the case, the addition of micromolar amounts of SA might overwhelm the control mechanism and allow enough accumulation of free SA in the phloem to induce resistance in the plant (Meyer et al., 1999). This experiment demonstrates that SA can be found in AMF hyphae, but more work is needed to determine if transport between plants occurs and if so, at what rate. 


\section{LITERATURE CITED}

Abelson, P. H. 1990. Inefficient remediation of groundwater pollution. Science 250:733.

Alexopoulos, C.J., Mims, C.W. and Blackwell, M. 1996. Introductory Mycology. John Wiley and Sons, Inc., New York, NY.

Agrawal, A. A., Tuzun, S. and Bent, E. 2000. Induced plant defenses against pathogens and herbivores. APS Press, St. Paul, MN.

Baker, K. F. and Cook, R. J. 1974. Biological control of plant pathogens. W. H. Freeman and Company, San Francisco.

Barksdale, T.H. 1969. Resistance of tomato seedling to early blight.

Phytopathology 59:443-446.

Berger, R. D., Bergamin Filho, A. and Amorim, L. 1997. Lesion expansion as an epidemic component. Phytopathology 87:1005-1013.

Borlaug, N. E. 1958. The use of multilineal or composite cultivars to control air borne epidemic disease of self-pollinated crop plants. Proc. 1st Int. Wheat Genetics Symp., University of Manitoba 12-26.

Brophy, L. S. and Mundt, C. C. 1991. Influence of plant spatial patterns on disease dynamics, plant competition and grain yield in genetically diverse wheat populations. Agric. Ecosys. Envir. 35:1-12

Browning, A. J. and Frey, K. J. 1969. Multiline cultivars as a means of disease control. Annu. Rev. Phytopathol. 7:355-382. 
Burdon, J. J., and Chilvers, G. A. 1976. Controlled environment experiments on epidemics of barley mildew in different density host stands. Oecologia 26:61-72.

Calonnec, A., Goyeau, H. and De Vallavieille-Pope, C. 1996. Effects of induced resistance on infection efficiency and sporulation of Puccinia striiformis on seedlings in cultivar mixtures and on field epidemics in pure stands. Eur. J. Plant Pathol. 102:733-741.

Conrath, U., Chen, Z., Ricigliano, J. R. and Klessig, D. F. 1995. Two inducers of plant defense responses, 2,6-dichloroisonicotinic acid and salicylic acid, inhibit catalase activity in tobacco. Plant Biology 92:7143-7147.

Chin, K. M. and Wolf, M. S. 1984. Selection on Erysiphe graminis in pure and mixed stands of barley. Plant Pathol. 33:89-100.

Darwin, C. 1872. On the origin of species by means of Natural Selection. 6th edition. London.

Enyedi, A. J., and Raskin, I. 1993. Induction of UDP-glucose: salicylic acid glucosyltransferase activity in tobacco mosaic virus-inoculated tobacco (Nicotiana tabacum) leaves. Plant Physiol. 101:1375-1380.

Farmer, E. E. and Ryan, C. A. 1990. Interplant communication: Airborne methyl jasmonate induces synthesis of proteinase inhibitors in plant leaves. Proc. Nat. Acad. Sci. USA. 87:7713-7716.

Garrett, K. A. and Mundt, C. C. 1999. Epidemiology in mixed host populations. Phytopathology 89:984-990. 
Garrett, K. A. and Mundt, C. C. 2000 . Host diversity can reduce potato late blight severity for focal and general patterns of primary inoculum. Phytopathology 90:1307-1312.

Goodman, R. N. and Novacky, A. J. 1994. The hypersensitive reaction in plants to pathogens. APS Press. St. Paul, MN.

Hammerschmidt, R. and Nicholson, R. L. 2000. A survey of plant defense responses to pathogens, APS Press. St. Paul, MN. 55-71.

Hussey, R.S. and Barker, K.R. 1973. A comparison of methods of collecting inocula of Meloidogyne spp., including a new technique. Plant Dis. Rep. 57:1025-1028.

Jones, J. B. and Jones, J. P. 1991. Compendium of tomato diseases. APS Press. St. Paul, MN.

Kousik, C. S. and Ritchie, D. F. 1996. Evaluation of bell pepper genotype mixture plantings against Bacterial Spot. Bio. and Cult. Tests for Cont. of Plant Dis. 11:95-96.

Lannou, C., De Vallavieille-Pope, C. and Goyeau, H. 1994. Host mixture efficacy in disease control: Effects of lesion growth analyzed through computersimulated epidemics. Plant Pathol. 43:651-662.

Lannou, C., De Vallavieille-Pope, C. and Goyeau, H. 1995. Induced resistance in host mixtures and its effect on disease control in computer-simulated epidemics. Plant Pathol. 44:478-489. 
Lee, H. and Raskin, I. 1999. Purification, cloning, and expression of a pathogen inducible UDP-glucose:salicylic acid glucosyltransferase from tobacco. J. Biol. Chem. 274:36637-36642.

Leonard, K. J. and Fry, W. E. 1989. Plant disease epidemiology: Genetics, resistance and management. McGraw-Hill Publishing Company, New York.

Littlefield, L. J. 1969. Flax rust resistance induced by prior inoculation with an avirulent race of Melampsora lini. Phytopathology 59:1323-1328.

Locke, B.S. 1948. Diseases in tomato and other Lycopersicon species. Phytopathology 38:937-942.

Maiero, M., Bean, G.A. and Ng, J.T. 1991. Toxin production by Alternaria solani and its related phytotoxicity to tomato breeding lines. Phytopathology 81: 10301033

Malamay, J., Carr, J. P., Klessig, D. F. and Raskin, I. 1990. Salicylic acid: A likely endogenous signal in the resistance response of tobacco to viral infection. Science 250:1002-1004.

Milligan, S.B., Bodeau, J., Yaghoobi, J., Kaloshian, I., Zabel, P. and Williamson, V.M. 1998. The root knot nematode resistance gene Mi from tomato is a member of the leucine zipper, nucleotide binding, leucine-rich repeat family of plant genes. Plant Cell 10:1307-1319.

Meyer, G.D., Capieau, K., Audenaert, K., Buchala, A., Metraux, J. and Hofte, M. 1999. Nanogram amounts of salicylic acid produced by the rhizobacterium Pseudomonas aeruginosa 7NSK2 activate the systemic acquired resistance pathway in bean. Mol. Plant Micr. Inter. 12:450-458. 
Mundt, C. C. and Leonard, K. J. 1986. Analysis of factors affecting disease increase and spread in mixtures of immune and susceptible plants in computersimulated epidemics. Phytopathology 76:832-840.

Ngugi, H. K., King, S. B., Holt, J. and Julien, A. M. 2001. Simultaneous temporal progress of sorghum anthracnose and leaf blight in crop mixtures with disparate patterns. Phytopathology 91:720-729.

Olsson, S. and Gerhardson, B. 1992. Effects of long-term barley monoculture on plant-affecting soil microbiota. Plant and Soil 143:1:99-108.

Rands, R. D. 1917. Early blight of potato and related plants. Wis. Agric. Exp. Stn. Res. Bull. 320

Reinbothe, S., Mollenhauer, B. and Reinbothe, C. 1994. JIPs and RIPs: The regulation of plant gene expression by jasmonates in response to environmental cues and pathogens. Plant Cell 6:1197-1209.

Rossi, M., Goggin, F. L., Milligan, S. M., Kaloshian, I., Ullman, D.E. and Williamson, V.M. 1998. The nematode resistance gene Mi of tomato confers resistance against the potato aphid. Proc. Natl. Acad. Sci. USA 95:9750-9754

Rotem, J. 2000. The genus Alternaria: Biology, epidemiology, and pathogenicity. The Princeton Press, Princeton, NJ.

Sembdner, G. and Parthier, B. 1993. The biochemistry and the physiological and molecular actions of jasmonates. Ann. Rev. of Plant Phys. and Plant Mol. Bio. 44:569-589.

Shulaev, V., Silverman, P. and Raskin, I. 1997. Airborne signaling by methyl salicylate in plant pathogen resistance. Nature 385:718-721. 
Spletzer, M. E. and Enyedi, A. J. 1999. Salicylic acid induces resistance to Alternaria solani in hydroponically grown tomato. Phytopathology 89:722-727.

Stancheva, J. 1991. Inheritance of the resistance to injuries on the growth mass caused by Alternaria solani in the tomato. Genet. Sel. 24:232-236.

de Vallavieille-Pope, C., Picard-Formery, H., Radulociv, S. and Johnson, R. 1990. Specific resistance factors to yellow rust in seedlings of some French wheat varieties and races of Puccinia striiformis. France Agronomie 10:103-113.

Van der Plank, J. E. 1968. Disease Resistance in Plants. Academic Press, New York.

van Loon, L. C., Bakker, P. A. H. M. and Pieterse, C. M. J. 1998. Systemic resistance induced by rhizosphere bacteria. Annu. Rev. Phytopathol. 36:453483.

Vernooij, B., Friedrich, L., Morse, A., Reist, R., Kolditz-Jawhar, R., Ward, E., Uknes, S., Kessmann, H. and Ryals, J. 1994. Salicylic acid is not the translocated signal responsible for inducing systemic acquired resistance but is required in signal transduction. The Plant Cell 6:959-965.

Williamson, V.M. 1998. Root-knot nematode resistance genes in tomato and their potential for future use. Annu. Rev. Phytopathol. 36:277-93.

Wilson, J. P., Gates, R. N. and Panwar, M.S. 2001. Dynamic multiline population approach to resistance gene management. Phytopathology 91:255-260.

Wolfe, M. S. and Barrett, J. A. 1980. Can we lead the pathogen astray? Plant Disease 64:148-153. 
Wolfe, M. S. 1985. The current status and prospects of multiline cultivars and cultivar mixtures for disease resistance. Annu. Rev. Phytopathol. 23:251-273.

Wolfe, M. S. 2000. Crop strength through diversity. Nature 406:681-682.

Yalpani, N., Silverman, P., Wilson, M.M.A., Klier, D.A. and Raskin, I. 1991. Salicylic acid is a systemic signal and an inducer of pathogenesis-related proteins in virus-infected tobacco. The Plant Cell 3:809-818.

Yan, Z., and Reddy, M. S. 1999. Evaluation of plant growth-promoting rhizobacteria (PGPR) for control of tomato early blight in the greenhouse and field. Bio. and Cult. Tests 15:122.

Zhu, Y., Chen, H., Fan, J., Wang, Y., Li, Y., Chen, J., Fan, J., Yang, S., Hu, L., Leung, H., Mew, T. W., Teng, P. S., Wang, Z. and Mundt, C. C. 2000. Genetic diversity and disease control in rice. Nature 406:718-720. 